\title{
EFFECTS OF CONSULTATION ON PROFESSIONAL LEARNING COMMUNITIES
}

A Dissertation Presented to
the Faculty of the Graduate School
University of Missouri-Columbia
In Partial Fulfillment
of the Requirements for the Degree
Doctor of Philosophy
by b. Preast
University of Missouri-Columbia
Dr. Matthew K. Burns, Dissertation Supervisor

July 2018 
The undersigned, appointed by the dean of the Graduate School, have examined the dissertation entitled

\section{EFFECTS OF CONSULTATION ON PROFESSIONAL LEARNING COMMUNITIES}

presented by June L. Preast, a candidate for the degree of doctor of philosophy, and hereby certify that, in their opinion, it is worthy of acceptance.

Professor Matthew K. Burns, Ph.D.

Professor T. Chris Riley-Tillman, Ph.D.

Professor Stephen P. Kilgus, Ph.D.

Professor Chad A. Rose, Ph.D. 


\section{ACKNOWLEDGEMENTS}

The current project and my doctoral experience would not have been possible without so many people. My sincerest appreciation goes to my advisor and Dissertation Chair, Dr. Matthew Burns. You saw more potential in me than I knew existed and have always provided encouragement and guidance to help me change the world. You helped me turn my passion for advocacy into research and I am a better School Psychologist because of you. I also want to extend my thanks to Dr. Chad Rose, Dissertation Committee Member, for your trust and support

through my doctoral experience. Thank you to my fellow graduate student and project right-hand woman, Lisa Aguilar. There is no way this project would have been executed as it was without your help and the time you dedicated. And thank you to my project observers and fellow graduate students, Crystal Taylor, Helen Young, Katie Eiben, and Karen Keltner.

Last but not least, I want to thank my incredible support system outside of Mizzou. To my mother, you taught me to question everything and never stand for the mistreatment of others. You created a culture of advocacy in our home that has fueled my career and I have full intentions of following in your footsteps throughout the rest of my life. To my father, you have given me more gifts than you could ever know. You taught me how to work hard to earn respect and recognition. You have been my rock during this journey and I could not have accomplished this without you. To my brother, extended family, and friends, I am incredibly lucky to have so many people who have loved and supported me through my prolonged status as a professional student. You have provided guidance, respite, meals, and so many other things for which I am so grateful. Thank you to my Southbrook family for giving this NC girl a home and a family away from home. And a last thank you so my spotted spaniels. You provided the cuddles I needed after hard days, walks to clear my head, and necessary breaks to keep my sanity. 


\section{TABLE OF CONTENTS}

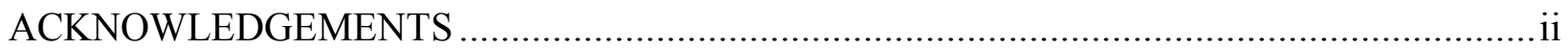

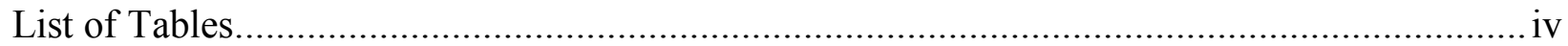

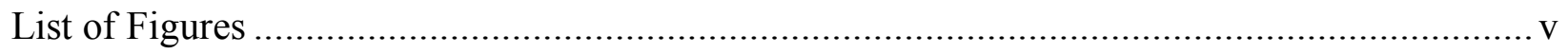

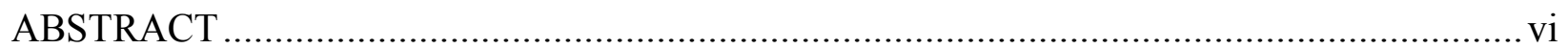

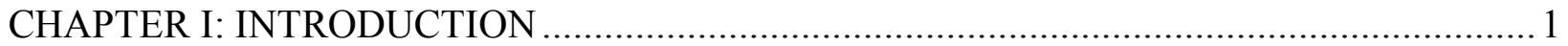

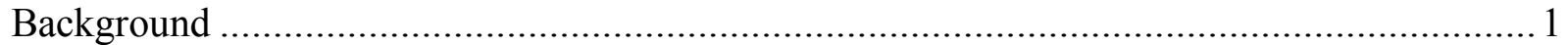

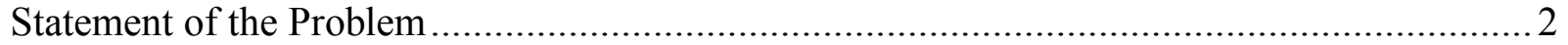

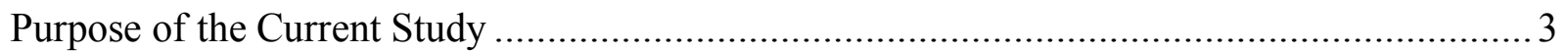

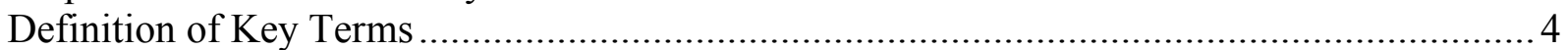

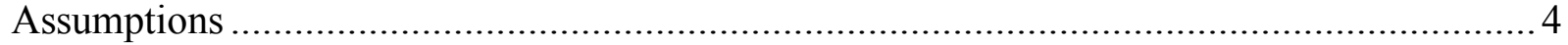

Delimitations …

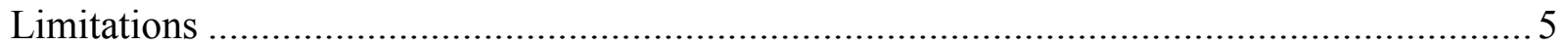

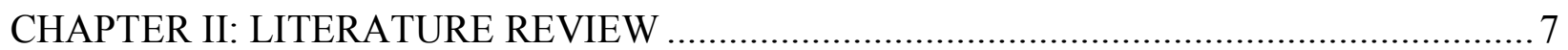

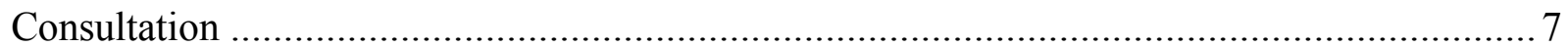

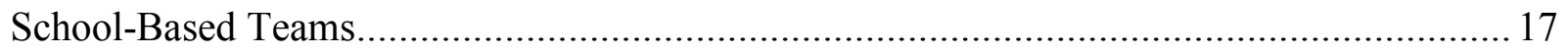

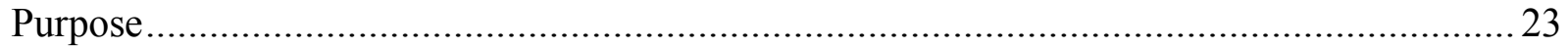

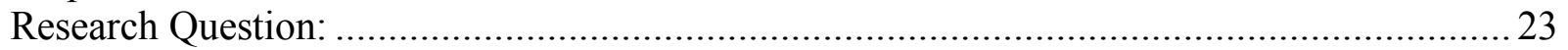

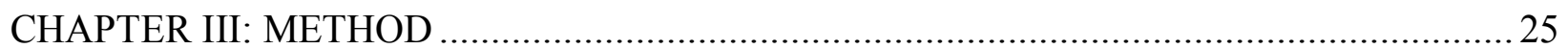

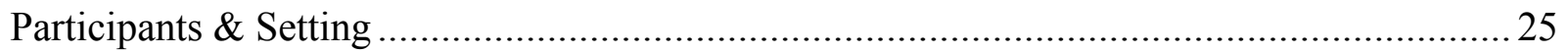

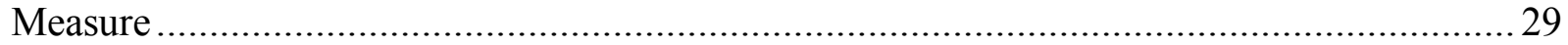

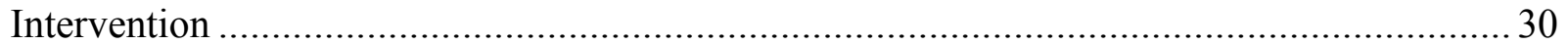

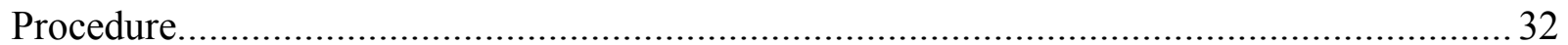

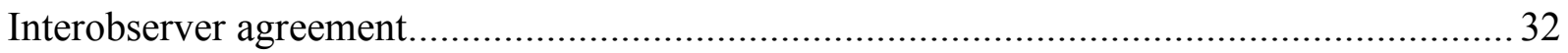

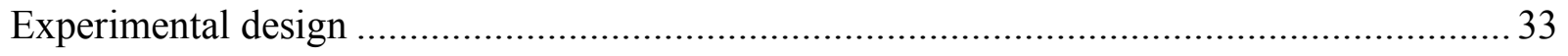

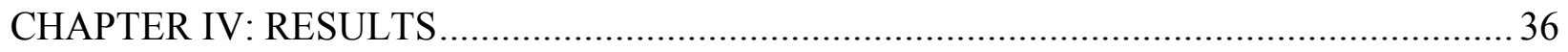

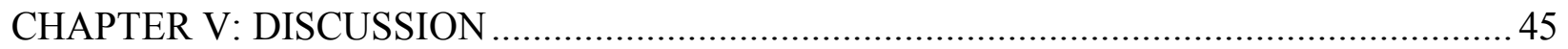

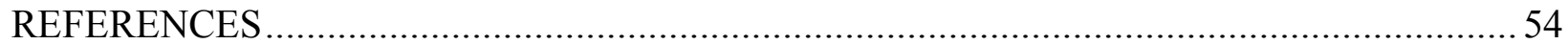

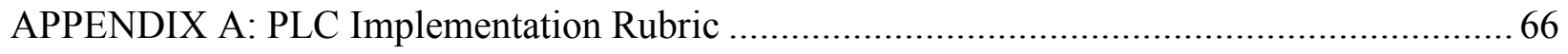

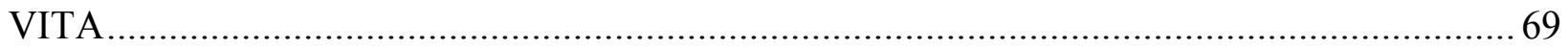




\section{List of Tables}

Table 1 Means and Standard Deviations of the Total Sum Average Implementation Scores across three Strands and Effect Sizes........................................................................ 39 Table 2 Means and Standard Deviations of the Total Sum Average Implementation Scores across Strand 4 and Effect Sizes........................................................................... 43 


\section{List of Figures}

Figure 1 Total Sum Average Implementation Scores across three strands....................... 40

Figure 2 Total Sum Average Implementation Scores across Strand 4 .......................... 44 


\begin{abstract}
School consultation has been used to increase fidelity of implementation for team processes (Burns, Peters, \& Noell, 2008) and resulting interventions (Noell, Witt, Gilbertson, Ranier, \& Freeland, 1997). Professional learning communities are teacher teams with the overall purpose of changing educator behavior through collaborative engagement with colleagues and use of data to inform instructional practices (DuFour, Eaker, \& DuFour, 2005; McLaughlin \& Talbert, 2006). School-based teams, such as problem-solving teams, do not often follow implementation guidelines (Burns \& Symington, 2002), thus hindering a crucial element of a successful response to intervention (RTI) model (Burns \& Coolong-Chaffin, 2006). The discussion of student data and intervention strategies happening within PLCs is important for the continuation of an RTI model within schools (Burns \& Gibbons, 2012).

The current study investigated the effects of consultation on PLC implementation fidelity for four fourth-grade teacher teams. The implementation of PLCs within Missouri schools was measured though an implementation rubric (PLC Implementation Rubric) that was designed to be used by PLC teams to self-assess their implementation formatively, and by PLC consultants as a summative assessment for each school (DESE, 2014). The current study used the items from the PLC Implementation Rubric that were observable during regular PLC team meetings. The observation tool was composed of the following strands: Strand \#4 How Effective Teams Work $(\alpha=.90)$, Strand \#5 What Students Need to Know and Do $(\alpha=.91)$, and Strand \#6 Assessment for/of Learning ( $\alpha=.86$ ) (Burns et al., in press). Data for the current study consisted of the observed implementation of each item within the three strands.

Each team was observed with the rubric using a multiple baseline design, including baseline, intervention, and maintenance phases. The intervention phase involved the researcher
\end{abstract}


providing consultation on an identified area of weakness and guiding the team through an intervention, using an instructional consultation framework. The results from the study indicated a change in PLC implementation when consultation was added. Each team displayed an improvement in their implementation of PLC practices that was maintained after consultation ended. However, the improvements for each team during the intervention and maintenance phases were small, in comparison to the baseline phase. Future research is needed to determine the impact of consultation with PLCs on student outcomes. Implications for research and practice, limitations, and future directions are discussed. 


\section{CHAPTER I: INTRODUCTION}

\section{Background}

School teams have become an integral part of the school environment. Teachers are considered to be more effective when given the opportunities to collaborate (Goldenberg, 2004). The overall purpose of professional learning communities (PLC) is to change educator behavior through collaborative engagement with colleagues (Thessin, 2015). PLCs have the potential to

change educational practices in schools, but student data were not used within their structure as a tool for guiding colleague collaboration until the 2000s (McLaughlin \& Talbert, 2006).

Education teams based in the schools, such as problem-solving teams, do not often follow implementation guidelines (Nellis, 2012). When all 50 states and the District of Columbia were surveyed on their state policies regarding educational teams, only $35 \%$ of states responded that their prereferral intervention teams were usually successful (Buck, Polloway, Smith-Thomas, \& Cook, 2003). Moreover, the interventions designed by teams are usually not implemented with fidelity, thus the intervention effectiveness is questionable (Flugum \& Reschly, 1994).

School consultation has been used to increase fidelity of implementation for team processes (Burns, Peters, \& Noell, 2008) and resulting interventions (Noell, Witt, Gilbertson, Ranier, \& Freeland, 1997). School consultation is defined as the process of the consultant providing educational and psychological services, through problem-solving and support, to a consultee with the aim of improving the educational services provided to a student or group of students (Erchul \& Martens, 2002). One of the core facets of school consultation is the application of prevention to various issues within the school (Erchul \& Martens, 2002). By having the consultant work with the school staff member to problem-solve and by having that consultant also provide support to the school staff member, the school staff member learns 
techniques and strategies to aid in their regular interactions with students. The information a school staff member learns from the problem-solving interaction with the consultant can then be used in the future, therefore providing the school staff member with the tools needed for a preventative approach (Erchul \& Martens, 2010).

The implementation integrity of interventions is key not only to ensuring that the student is receiving appropriate help for their learning difficulties, but it is also key to the problemsolving model (Burns \& Coolong-Chaffin, 2006; Noell \& Gansle 2006; Noell, Duhon, Gatti, \& Connell, 2002). Throughout the problem-solving process, data are collected to evaluate the instructional needs of the student and the effectiveness of the intervention for the student. Educational decisions made using data from interventions that were not implemented with integrity and/or fidelity is similar to determining special education eligibility without doing anything (Noell \& Gansle, 2006). Not only is implementation integrity important for individual interventions, it is a crucial element of a successful response to intervention (RTI) model (Burns

\& Coolong-Chaffin, 2006). The discussion of student data and intervention strategies happening within PLCs is important for the continuation of an RTI model within schools (Burns \& Gibbons, 2012).

\section{Statement of the Problem}

Evidence is scarce regarding the effectiveness of PLC implementation in schools, and inconsistent implementation practices have plagued school-based teams (Buck, Polloway, SmithThomas, \& Cook, 2003). Student academic performance increases with problem-solving team (PST) involvement, but only with high implementation of the PST (Kovaleski, Gickling, Morrow, \& Swank, 1999). Following consultant provided performance feedback, PST 
participants did not maintain intervention implementation fidelity (Burns et al., 2008). Research is need to examine implementation fidelity of PLCs.

\section{Purpose of the Current Study}

Research is available addressing the effect of behavioral consultation on implementation of treatment plans in schools with and without performance feedback. Literature also exists outlining the effects of performance feedback on the implementation integrity of PSTs (Burns et al., 2008). However, little research is available examining the effects of consultation on the implementation fidelity of the PLCs. Therefore, the proposed study will examine effects of consultation to the teachers on the implementation fidelity of the PLC.

The study will be guided by the following question:

\section{Research Question:}

1. What is the effect of consultation with teachers on the implementation fidelity of professional learning communities?

Given the review of research, it is hypothesized that the consultation provided to the professional learning community will lead to higher implementation fidelity of the professional learning community. 


\section{Definition of Key Terms}

Professional Learning Communities (PLC): PLCs are teams of teachers with the purpose of changing educator behavior through collaborative engagement with colleagues (DuFour, Eaker, \& DuFour, 2005).

Instructional Consultation: An indirect service delivery model aimed at improving student achievement and performance by focusing on both the content and processes of instruction (Rosenfield, 1987, 2002).

Corollary Questions: A set of questions aimed at ensuring discussion of student progress through collaboration within PLCs (DuFour \& Eaker, 1998). The four corollary questions for PLCs used in the current study are: What do we expect our students to learn? How will we know they are learning? How will we respond when they do not learn? and How will we respond if they already know it?

\section{Assumptions}

There are several underlying assumptions regarding this study. First, it is assumed that teachers have participated in PLCs prior to the beginning of the study and are familiar with the process. Second, it is assumed that the teacher participants are typical teachers who engage in instruction similar to other teachers. Third, it is also assumed that what occurs in the PLC meetings will affect broader teacher practices. A fourth assumption is that any change in teacher instruction will be demonstrated through student performance data. Last, it is assumed that three strands used from the PLC implementation rubric will adequately capture the general PLC practices. 


\section{Delimitations}

For this study, there are four delimitations that predetermine the boundaries and limit the study. First, the teachers from only elementary school will be chosen for the study, which limits the generalizability of PLC implementation fidelity with schools of higher grade levels. However, using one school could enhance the internal validity of the conclusions. Additionally, instructional consultation will be the consultation model used, which limits the consultation practices but helps focus the consultant's activities and increases likelihood of replication. Lastly, the PLC implementation rubric strands to be observed were chosen because they are considered to be easily observable within a weekly PLC meeting, which limits the data and does not examine other potential aspects of an effective PLC.

\section{Limitations}

There are three possible limitations that may occur during the course of this study. First, some of the PLC teams may be participating in the Missouri PLC Essential Curriculum with occasional PLC consultant support, while other PLC teams may not. Second, teacher instruction will not be assessed, limiting the PLC effect on instructional change. A third limitation is that administrator support for PLC implementation will not be known, limiting the understanding of the effects of support for PLC implementation within the school.

\section{Organization of the Dissertation}

This dissertation contains four additional chapters that outline the study, describe key features, and discuss findings related to research and practice. Chapter 2 contains a literature review, which defines theoretical components related to consultation, describes features of school-based teams, and using professional learning community practices. Chapter 3 contains the Methods of the study, and describes the participants and school setting, observation measure, 
conditions, procedures, and how the data were analyzed. Chapter 4 contains the Results of the question explored in this study. Chapter 5 contains the Discussion, and reviews the findings of the study, provides implications for research and practice, discusses limitations, and provides future directions for research. 


\section{CHAPTER II: LITERATURE REVIEW}

This chapter reviews relevant literature for the study's purpose. First, research regarding four forms of consultation will be examined. Then, literature for school-based teams, in particular professional learning communities, will be reviewed.

\section{Consultation}

Caplan (1963) defined consultation as the interaction between the consultant, or the specialist, and the consultee to aid the consultee with an issue of difficulty that is considered to be within the consultant's area of expertise. The issue of difficulty is between the consultee and the client where the consultant is providing aid to the consultee for the consultee to implement a plan or manage strategies for the client (Caplan, 1963). Caplan's development of this definition of consultation stems from social influence theory, which is the idea that an individual will change their belief or attitude after being persuaded by the action or presence of an influential individual (Caplan, 1963; Erchul \& Martens, 2002), and from a desire to have a broader professional impact. A consultant providing strategies and services to a consultee that then provides services to the clients, means that more people are receiving aid than if the consultant were to provide aid to the client directly (Gutkin \& Curtis, 2009; Zins, Kratochwill, \& Elliott, 1993; Erchul \& Martens, 2002).

School consultation applies the general idea of consulting to a specific setting, and is defined as the process of the consultant providing educational and psychological services, through problem-solving and support, to a consultee with the aim of improving the educational services provided to a student or group of students (Sheridan \& Gutkin, 2000). School consultation is also shaped by social influence theory, but is also guided by prevention (Erchul \& Martens, 2002). By having the consultant work with the school staff member to problem-solve 
and by having that consultant also provide support to the school staff member, the school staff member learns techniques and strategies to aid in their regular interactions with students. The information a school staff member learns from the problem-solving interaction with the consultant can then be used in the future, therefore providing the school staff member with the tools needed that can be applied much sooner in the problem-solving process than to wait for a behavior to fully manifest itself.

School consultation generally takes one of three forms (Sheridan, Welch, \& Orme, 1996). Below, I will discuss three forms of consultation in schools (collaborative consultation, instructional consultation, and behavioral consultation), as well as, define each, provide examples of each, and examine research regarding each consultation process. Additionally, I will discuss systems consultation and examine its research base.

\section{Collaborative Consultation}

Collaborative consultation is defined as a consultant helping a consultee implement strategies to improve the educational outcomes of a client in a non-hierarchical relationship between the consultant and consultee (Kampwirth, 2003). Collaboration between the consultant and consultee is considered foundational to consultation service delivery models (Gutkin, 1999a), but has been an area of considerable debate. Gutkin (1999a) reinterpreted previous consultation studies that argued against collaboration in school consultation (Ercul, 1987; Erchul \& Chewing, 1990; Witt, Erchul, McKee, Pardue, \& Wickstrom, 1991) by stating that the consultation dyads of the previous studies were not absent of collaboration through a vague definition of collaborative consultation. Erchul (1999) contended that without an operational definition of collaborative consultation, its science cannot effectively inform practice. Despite the call for an operational definition of collaborative consultation, Gutkin (1999b) argued the that 
daily meaning of collaboration was sufficient as the restrictiveness of operational definitions ignores the complicated phenomena in schools influencing school psychologist practice. However, as disputed by Erchul (1999), Gutkin's argument against an operational definition failed to incorporate the perspective of the consultee/consultant relationship and the role of social influence. Collaboration occurs within school consultation, but the lack of operational definition for collaborative consultation has resulted in insufficient evidence on the effectiveness of collaborative consultation on student outcomes.

Theoretical underpinnings. Tharp and Wetzel's (1969) and Tharp's (1975) triadic model of consultation influenced the development of the collaborative consultation model (Idol, Paolucci-Whitcomb, \& Nevin, 1986). The triadic consultation model involves three individuals: the consultant, the mediator, and the target (Tharp \& Wetzel, 1969; Tharp, 1975). In the collaborative consultation model, the consultant and teacher, or mediator, share their expertise with each other and share responsibility of educational decisions for the student, or target (Idol et al., 1986). Cooperation is a key element of collaborative consultation and should occur as the consultant and teacher work together to address student problems (Idol et al., 1986). The cooperation element of collaborative consultation stems from the social psychological construct of positive goal interdependence (Deutsch, 1949; Johnson \& Johnson, 1975; Idol et al., 1986). The teacher and consultant work together to reach the same goals for the student with the understanding that goal attainment is achieved through cooperation (Idol et al., 1986).

Research. Many of the articles about collaborative consultation do not provide evidence of effectiveness through research, rather effectiveness of this consultation model is often from the vast consultation experience of the authors (Nevin, Thousand, Paolucci-Whitcomb, \& Villa, 1990; Villa, Thousand, Paolucci-Whitcomb, \& Nevin, 1990). Strickler et al. (2014) used a case 
example approach to demonstrate collaborative consultation when addressing the needs of a teenager in the foster care system. Several individuals involved in the teenager's life met in a collaborative fashion to plan possible solutions to his situation. Both the individuals involved in the collaborative meeting and the teenager voiced positive impressions of the collaborative consultation approach. The authors indicated that they used a framework for measuring the effectiveness of the collaborative consultation process, but provided no information regarding the team practices within said framework. Moreover, it was not stated if the teenager met the desired outcomes of the collaborative team.

Kemmis and Dunn (1996) examined success of occupational therapy interventions when designed and implemented through a collaborative consultation framework. A total of 213 interventions were designed for 10 students through the weekly collaborative consultation meetings of the occupational therapist and teacher. The interventions designed through collaborative consultation and implemented by teachers had an average success rate of $63 \%$. It is important to note that no comparison was provided to demonstrate the rate of success for occupational therapy interventions when not designed through a collaborative consultation approach.

The key component in collaborative consultation is the non-hierarchical relationship between consultant and consultee (Kampwirth, 2003). However, little evidence is available on the effectiveness of a non-hierarchical relationship in consultation. Using previous studies on consultation in schools, Erchul (1992) suggested that the idea of a collaborative relationship in consultation should be reframed to be a cooperative relationship. Previous consultation studies investigating communication styles demonstrated that consultation was viewed as more effective when consultants demonstrated dominance and when consultees followed the lead of their 
consultants (Erchul, 1992). It appears that hierarchical relationships are an important component of effective consultation practices; however, most research regarding collaborative consultation is at least a decade old.

\section{Instructional Consultation}

Instructional consultation aims to improve student achievement and performance by focusing on both the content and processes of instruction (Rosenfield, 1987, 2002). Instructional consultation is most often facilitated by instructional consultation teams, a school team designed to provide structured collaboration with teachers to improve student outcomes (Rosenfield, 2002).

Theoretical underpinnings. The instructional consultation model was developed from social development theory (Vygotsky, 1962, 1978). Social development theory considers the context when examining student behavior or learning, as well as the development of the student within that context (Knotek, Rosenfield, Gravois, \& Babinski, 2003). Within the instructional consutlation model, the student is viewed as the unit of analysis and problem-solving revolves the environment and instruction surrounding the student (Rosenfield, Gravois, \& Silva, 2014).

Research. A total of 274 teachers were surveyed on their participation with instructional consultation, with 79 teachers participating in interviews regarding the level of instructional consultation implementation (Kaiser, Rosenfield, \& Gravois, 2009). The majority of teachers $(93.5 \%)$ reported satisfaction with the instructional consultation model (Kaiser et al., 2009). Teacher satisfaction and their perceptions of student outcomes were significantly related $(\mathrm{r}=.37$, $\mathrm{p}<.01$ ) (Kaiser et al., 2009). However, no significant relationship was found between teachers' satisfaction and teachers' use of instructional consultation with other students (Kaiser et al., 2009). 
Vu et al. (2013) examined the effectiveness of instructional consultation teams on teacher beliefs and practices in a 3-year implementation study. A total of 34 schools participated, with 17 assigned to have the instructional consultation teams treatment and 17 assigned to the control treatment. After the second year of implementation, teachers receiving the treatment reported higher levels of efficacy than teachers in the control condition $(d=0.04$ to 0.16$)$. Following the third year of implementation, teachers collaborating with instructional consultation teams again reported higher levels of efficacy ( $d=0.00$ to 0.15$)$, as well as, higher levels of collaboration $(d$ $=0.03$ to 0.22 ) than teachers in the control conditions. While teachers are reporting higher levels of satisfaction, efficacy, and collaboration with instructional consultation methods, student outcomes are not reported. The lack of reported student outcomes indicates a need for emphasizing student data, especially as the goals of instructional consultation are to improve student achievement and performance.

\section{Behavioral/ Problem-solving Consultation}

Bergan's behavioral consultation model is defined as the process of problem-solving between a consultant and consultee that uses behavioral analysis and technology to develop intervention plans and evaluate their effectiveness (Erchul \& Martens, 2002). Behavioral consultation is reliant upon the active participation of the consultee, as the consultant has little or no interaction with the client (Martens, DiGennaro Reed, \& Magnusson, 2014).

Theoretical underpinnings. Bergan's model of behavioral consultation was developed from the ideas of the D'Zurilla and Goldfried's (1971) problem-solving model, Tharp and Wetzel's (1969) application of behavior modification in natural settings, and other approaches. D'Zurilla and Goldfried's (1971) problem solving model is defined as the process of increasing the probability of the selection of the most effective strategy by providing individuals with 
several potentially effective strategies. Tharp and Wetzel's (1969) application of behavior modification in natural settings extended the behavioral approach to therapy to natural settings and characterized the role of care providers to be the behavior change agents (Erchul \& Martens, 2002). The behavioral consultation model integrates elements of both the problem-solving model and the application of behavior modification to natural settings.

Research. Behavioral consultation methods are widely used within schools due to the empirical effectiveness in producing behavioral change. In a review of consultation research from 1985 to 1995 , Sheridan et al. (1996) reported that $44 \%$ of the 48 studies found involved behavioral consultation, more than any other form of consultation. Of those behavioral consultation studies coded, $95 \%$ reported at least one positive outcome with $89 \%$ of the total outcomes reported in the positive direction (Sheridan et al., 1996). Those positive outcomes have been seen in student behavior change (Noell et al., 2005). When teachers received performance feedback through behavioral consultation, student behavior outcomes were significantly higher than when teachers received just weekly meetings or commitment emphasis $\left(\eta^{2}=.36, \mathrm{p}<.001\right)$ (Noell et al., 2005).

Fuchs, Fuchs, and Bahr (1990) trained school-based consultants in behavioral consultation methods and compared the results of students brought before the consultants and those students who remained in the control group. Students whose teachers worked with consultants referred a significantly lower amount of students to special education than those in the control group, $\chi^{2}(2, N=36)=10.19, p<.01$ (Fuchs et al., 1990). Gutkin, Henning-Stout, and Piersel (1988) examined the service delivery of school psychologists in a district that implemented district-wide behavioral consultation methodology for their prereferral intervention teams. After comparing data 2 years prior to behavioral consultation implementation and 4 years 
following implementation, the average students served by school psychologists increased from 80.9 to 92.0 , the students meeting their educational outcomes without special education increased from $21 \%$ to $61 \%$, and the special education eligibility of students tested increased from $69 \%$ to $82 \%$ (Gutkin et al., 1988). Behavioral consultation implementation has led to improved student academic outcomes, decreasing the amount of special education referrals and testing.

\section{Systems Consultation}

Systems consultation involves working with schools and school systems to address issues in education by implementing preventative methods (Shapiro, 2000). School psychologists are apt to consult on systems-level changes due to the breadth and depth of training. Additionally, systems change is influenced by the leaders involved (Castillo \& Curtis, 2014).

Theoretical underpinnings. Adelman and Taylor (1997) conceived a four phase conceptual framework for addressing school systems reform, (a) creating readiness, (b) initial implementation, (c) institutionalization, and (d) ongoing evolution. Curtis and Castillo (2014) identified the following seven principles critical to school organizational change: leadership; involvement of key stakeholders; shared vision, mission, beliefs, and values; having a systems perspective; data-based decision making; capacity building; and planning and problem-solving skills. Systems consultation integrates both the framework from Adelman \& Taylor (1997) and the principles of organizational change.

Research. The literature base for systems consultation and how to affect educational reform continues to grow. However, that literature base includes few empirical studies examining the effects of systems consultation. The small number of studies regarding systems consultation is probably due to the difficulty in enacting and maintaining educational reform 
efforts. In a case study of a system level intervention in a school for children with disabilities, intervention efforts and perceptions of change increased during the two years following implementation (Curtis \& Metz, 1986). Additionally, requests for indirect school psychological services from the staff increased. There is potential for achieving sustainable educational reform. Four schools continued to improve their practices and outcomes regarding reading and behavior four years after initial systems-level consultation implementation (Ervin, Schaughency, Goodman, McGlinchey, \& Matthews, 2006). Each school is a dynamic system, with specific needs influencing systems-level work.

\section{School Psychologists as Consultants}

It is essential for school psychologists to possess skills in consultation and problemsolving in order for them to effect outcomes for all students at the individual, classroom, school, or district levels (Ysseldyke et al., 2006). Burns and Coolong-Chaffin (2006) described in detail the roles a school psychologist can play throughout the problem-solving process for their schools. School psychologists can consult with teachers on their curriculum, administrators on the assessment systems being used, and promote research-based RTI activities and implementation. Assessment and data-based decision making is considered an optimal placement for school psychological services as school psychologists are well versed in various forms of assessment and can help determine the appropriate tools for a variety of student difficulties. School psychologists can inform teachers and school personnel about effective, intensive interventions to address the learning difficulties for individual students (Burns \& CoolongChaffin, 2006).

In a survey of 249 practicing school psychologists in California, $41 \%$ of respondents indicated that they participated in consultation with teachers on a regular basis (Powers, Hagans, 
\& Busse, 2008). It should be noted that the effectiveness of the school psychologist consultation with teachers was not measured and therefore unknown (Powers et al., 2008). Results from a mixed-methods study indicate promising trends in school psychologist consultation on early career teachers' effectiveness and connectedness (Shernoff et al., 2016). After reviewing 47 meta-analyses that corresponded to the domains outlined by Ysseldyke et al. (2006), Burns, Kanive, Zaslofsky, and Parker (2013) found support for school psychologist practice across the domains $(d=0.40)$, but did not explicitly examine consultation by school psychologists. The results of the Burns et al. (2013) second-level meta-analysis suggested that school psychologists can be effective in influencing school decisions and practices across universal, classroom, and individual levels, but more research is needed regarding consultation.

\section{Synthesis}

School consultation is based on Caplan's (1963) approach to consultation and social influence, but is also heavily influenced by problem solving and prevention. Several models of consultation have been used within schools, but little empirical evidence is available on the effectiveness of most of these consultation models. Collaborative consultation has been discussed within schools over the past 20 or more years, but research on its effectiveness stems from the experiences of the researchers, with no data to support it (Nevin et al., 1990; Villa et al.,1990). Teachers reported higher levels of satisfaction, efficacy, and collaboration when using instructional consultation methods, but research on this consultation model neglected to report its effectiveness, or lack thereof, on student achievement and performance (Vu et al., 2013; Kaiser et al., 2009). Behavioral consultation is the most widely researched consultation model in schools and is supported by studies indicating positive outcomes and significant changes in student behaviors (Sheridan et al., 1996; Noell et al., 2005; Gutkin et al., 1988; Fuchs et al., 
1990). Requests for indirect school psychological services may increase as systems-level change is implemented and maintained (Curtis \& Metz, 1986). School psychologists are not only considered to be in optimal positions for affecting change in schools, research supports the effectiveness of school psychologists influencing decisions at the individual, classroom, school, and district levels (Ysseldyke et al., 2006; Burns \& Coolong-Chaffin, 2006; Burns et al., 2013; Shernoff et al., 2016). As school psychologists are able to provide schools with a knowledge base pertaining to academics, behavior, and consultation, their involvement consulting with teams can help address big problems in education (Shapiro, 2000).

\section{School-Based Teams}

School teams have become an integral part of the school environment. Teachers are considered to be more effective when given the opportunities to collaborate (Goldenberg, 2004). McLaughlin and Talbert (2006) identified the following characteristics of effective teacher teams: identifying and sharing goals, assessing goal progress, making necessary instructional adjustments, and providing accountability among members of the team. Student achievement improves when teachers focus on student learning, versus focusing on teacher relations and satisfaction (Goldenberg, 2004). Bransford and Stein (1984) developed the IDEAL problemsolving model, with the following components: (a) problem identification, (b) problem definition, (c) alternative solutions exploration, (d) solution application, and (e) solution effectiveness examination. Methods for addressing problems often stem from the IDEAL problem-solving model, especially the methods utilized in schools. Below, I will discuss three types of school-based teams (professional learning communities, pre-referral intervention teams, and problem-solving teams), as well as, define each, provide examples of each, and examine research regarding each school-based team. 


\section{Professional Learning Communities}

Professional learning communities (PLCs) emerged from companies and businesses bringing attention to the impact of workplace settings on its workers (Hord, 1997). The private sector used the term learning organizations for defining problem solving within the workplace by encouraging workers to participate in collaboration (Hord, 1997). Senge (1990) described learning organizations as "where people continually expand their capacity to create the results they truly desire, where new and expansive patterns of thinking are nurtured, where collective aspiration is set free, and where people are continually learning how to learn together" (p.3). As the suggestions made by Senge (1990) were adopted by education, educators began using the term learning communities (Hord, 1997).

The overall purpose of PLCs is to change educator behavior through collaborative engagement with colleagues (DuFour, Eaker, \& DuFour, 2005). PLCs have potential to change educational practices in schools, but student data were not used within their structure as a tool for guiding colleague collaboration until the 2000s (McLaughlin \& Talbert, 2006). PLC members continue to display difficulties in using student data throughout multiple research studies. Sigurðardóttir (2010) examined the relationship between PLC effectiveness and teacher PLC perception in elementary schools in Iceland. A moderate relationship was found between teacher perception and PLC effectiveness $(r=.52)$, in addition to improved mathematics achievement in students (Sigurðardóttir, 2010). In a study of 24 schools over 3 years, Louis and Marks (1998) found a positive relationship $(r=.36)$ between academic performance with authentic learning and professional community. Andrews and Louis (2007) investigated the impact of a PLC model on student behavioral difficulties. While behavioral difficulties decreased, student achievement data were not reported and student outcomes were based on teacher perceptions (Andrews \& 
Louis, 2007). A link appears to exist between student achievement and PLC implementation, but more research is needed.

\section{Prereferral Intervention Teams}

Graden, Casey, and Christenson (1985) presented the Prereferral Intervention Team (PIT) model as a way to provide support to students who are having difficulty learning but who are not considered to be appropriate for special education. Graden et al. (1985) define the PIT model as a method to support students experiencing academic and/or behavioral difficulties through a collaborative problem-solving approach. While PITs have been referred to by a variety of different names, Instructional Support Teams (Kovaleski, Tucker, \& Duffy, 1995), Mainstream Assistance Teams (Fuchs et al., 1990), and Teacher Assistance Teams (Chalfant, Pysh, \& Moultrie, 1979) to name a few, all of the teams function on the premise of using a multidisciplinary team to address instructional difficulties of students in general education through developing intervention plans (Burns, Vanderwood, \& Ruby, 2005). Graden et al. (1985) outlined the following procedures that the aforementioned models generally follow: request for consultation, individual consultation, observation (if needed), conference, and referral to special education.

Burns and Symington (2002) conducted a meta-analysis on the research regarding prereferral intervention teams, specifically the effect on student and systemic outcomes. Student outcomes included task completion, observations of target behavior, observations of time ontask, and score on behavior rating scales. Systemic outcomes included referrals to special education, new placements in special education, percentage of new referrals to special education being designated as having a disability, student retention by grade, and an increase in the consulting and/or counseling activity of the school psychologists. After reviewing nine articles 
that met the inclusion criteria, the study found all but two of the included studies had strong effects on the desired student $(d=1.15)$ and systemic outcomes $(d=0.90)$. It is important to note that 72 articles were reviewed and only 9 met the inclusion criteria for the authors, indicating that multiple articles discussed PITs, but few examined quantitative data for the effectiveness of the teams. Young and Gaughan (2010) examined the implementation of the problem-solving model over 4 years, and focused on the amount of time teachers spent at each stage of the problem-solving process and the amount of time spent considering factors associated with student functioning. Results indicated successful PITs involve the following: adequate training, administrative support, multidisciplinary membership, and adherence to a structured problemsolving process.

PITs have demonstrated high acceptability of the organizational consultation process, acceptability of the adopted changes, and all of the adopted changes were supported one year later (Truscott, Cosgrove, Meyers, \& Eidle-Barkman, 2000). Teachers expected support from the PIT in form of acquiring interventions, providing professional support, and informing the parents of a concern (Lane, Mahdavi, \& Borthwick-Duffy, 2003). Moreover, more than half of the teachers wanted support in implementing interventions and wanted follow-up assistance. The studies summarized above indicate the acceptability among teachers of a problem-solving process and the need for additional support for teachers to implement the interventions resulting from this process (Truscott et al., 2000; Lane et al., 2003).

\section{Problem-Solving Teams}

While the original model of PITs was to provide a collaborative approach to address student needs outside of special education (Graden et al., 1985), their function has evolved to be the intervention step required to make a referral for special education testing (Burns et al., 2005). 
In contrast to PITs, problem-solving teams (PST) use student data to implement an intensive collaborative service delivery model (Tilly, 2002).

Inconsistent implementation practices have plagued PST and PIT models across schools (Buck, Polloway, Smith-Thomas, \& Cook, 2003). Students with access to a PST displayed greater academic performance when compared to students without access to a PST, but only when that PST had a high level of implementation (Kovaleski et al., 1999). Burns, Peters, and Noell (2008) examined the implementation fidelity of PSTs with the addition of performance feedback on team processes. The performance feedback intervention resulted in an increase in PST implementation fidelity with an average of $94 \%$ of non-overlapping pairs of intervention data to baseline data (Burns et al., 2008). However, even with receiving performance feedback, PSTs did not continue monitoring student progress, determine intervention effectiveness, or implement the interventions with fidelity.

\section{Group Dynamics}

Individuals are influenced not only by their separate interactions, but also by the groups with which they associate. Teachers and the teams in which they participate are no different. Below I will identify theories that influence group dynamics. Social identity theory describes how individuals identify themselves based upon their group memberships (Tajfel, 1978). Within social identity theory it is observed that individuals categorize themselves into groups, they identify with groups, and they also compare themselves to other groups. Self-categorization theory (Turner, 1985) is the idea of individuals assuming the values of the group for the purpose of that group and thereby categorize themselves by the values of the group. Teachers who strongly identify with their profession view their job as more significant and meaningful $(r=$ $0.40)$ and have higher motivation $(r=0.56)$ and satisfaction $(r=0.50)$ (van Dick \& Wagner, 
2002). Similarly to the social identity theory, teachers may identify with a group and then adapt their values to match those of the group. The interaction of individuals in groups directly influences not only the group's performance, but also that of the individual.

Social facilitation (Zajonc, 1965) is the idea that performance changes on simple and complex tasks when alone or in the presence of a group. In a meta-analysis of 78 studies on social facilitation, expectations of co-worker performance $(d=0.45)$, task meaningfulness $(d=$ $0.90)$, culture $(d=0.46)$, and evaluation potential $(d=0.59)$ demonstrated strong influences on group individuals exerting less effort due to the presence of others (Karau \& Williams, 1993). While individuals may exert less effort when participating in a group versus individually, research in re-education training indicated that the practice and philosophy of a small group is easier to change than that of an individual (Lewin \& Grabbe, 1945). Group decision is influenced by the group impact on the individual's readiness to change and the motivation of the group (Lewin, 1952). In order for a group to successfully change, the group must break away from current practices, adopt a new level of practice, and maintain that new level of practice (Lewin, 1952). More recent research continues the supposition that in order to make changes in instructional practices, teachers must use and maintain the newly adopted practice (Little, 2002).

\section{Synthesis}

School-based teams continue to function within schools, whether in the form of PLCs, PITs, or PSTs and all function with the idea of improving education for students. While the theory behind school-based teams is sound, evidence is scarce on effectiveness for improving student outcomes, in particular for PLCs. PLC literature is mainly qualitative and focuses on teacher perceptions. Two studies indicated improved student achievement following PLC implementation, but are limited by the lack of emphasis on making decisions within the PLC 
based upon student data (Sigurðardóttir, 2010; Louis \& Marks, 1998). More empirical evidence is available for PITs and PSTs, but, each of these methods focus on individual students versus teacher practices affecting a classroom of students (Burns \& Symington, 2002; Graden et al., 1985). Evidence suggests that teachers are apt to receive consultation with their problem-solving processes and intervention implementation (Truscott et al., 2000; Lane et al., 2003).

Additionally, changes can be made within education if teachers are willing to adopt and maintain new practices (Lewin, 1952; Little, 2002). The lack of emphasis on student data during PLC processes in research studies may be due to the support needed by teachers participating in PLCs.

\section{Purpose}

Research is available addressing the effect of behavioral consultation on implementation of treatment plans in schools with and without performance feedback. Literature also exists outlining the effects of performance feedback on the implementation integrity of PSTs (Burns et al., 2008). However, little research is available examining the effects of school psychologist consultation on the implementation fidelity of the PLCs. Therefore, the proposed study will examine effects of the consultation provided by the school psychologist to the teachers on the implementation fidelity of the PLC. As school psychologists are able to provide schools with a knowledge base pertaining to academics, behavior, and consultation, their involvement with PLCs can help address big problems in education (Shapiro, 2000).

The study will be guided by the following question:

\section{Research Question:}

1. What is the effect of consultation with teachers on the implementation fidelity of professional learning communities? 
It was hypothesized that consultation with the PLCs will lead to higher implementation fidelity of the PLC. 


\section{CHAPTER III: METHOD}

This chapter focuses on the research methods of this study. The following sections are discussed, (a) participants and setting, (b) measurement, (c) intervention, (d) procedure, (e) interobserver agreement, and (f) experimental design.

\section{Participants \& Setting}

The participants for the study were the members of four PLCs, which consisted of fourthgrade and/or combined fourth-grade and fifth-grade teachers who met weekly to discuss instruction. The PLCs teams met once each week. The PLCs were from schools within a suburban area in a Midwestern state. Recruitment of schools was based on number of teachers in fourth grade and interest of schools. The PLC teams participating in the study were required to have between three and four teachers providing instruction in the fourth grade. Interested schools were determined after contacting the school psychologist of schools with the appropriate number of fourth grade teachers. Each school provided instruction in reading and mathematics aligned with the Missouri essential curriculum, or state learning standards, provided by the school district (DESE, 2014). Each school chooses the curriculum as long as the students are meeting instructional standards according to the school district timeline. The recruitment of PLC teams took place across a 1 month period and were added to the study in order of acceptance of participation.

Team 1. The first team (Team 1) was within a K-5 school that utilized a multi-age approach to grade-level assignments. A total of 215 students attended the school, 49\% of which were eligible for a free or reduced price lunch (FRPL) and 7.3\% received special education services. The student population was majority Caucasian (63.3\%), 22.9\% African-American, 
$7.0 \%$ Multiple races, $5.6 \%$ Hispanic, $1.4 \%$ Asian-American, and $0.9 \%$ Native-American. The $4^{\text {th }}$ and $5^{\text {th }}$ grades consisted of 59 students.

The Team 1 members were the teachers providing instruction to students in the fourth and fifth grades, all of which attended the meeting regularly in one of the teacher's classrooms. The school counselor participated in all but one of the meetings, and the principal and school psychologist participated in three meetings each. Team 1 met regularly once per week to discuss lesson planning, scheduling, and various student or classroom activities. The meetings were held in one of the teachers' classrooms and lasted between 35 to 45 minutes. The members of Team 1 consisted of three Caucasian females, one had obtained an Educational Specialist degree and two had obtained a Bachelors degree. Team 1 teachers had an average of 12 years of teaching experience and an average of 4.7 years of experience in teaching the current grade. The reading curriculum taught at the first school was Good Habits, Great Readers (Klein, Fisher, \& Frey, 2012) and the Units of Study for Teaching Reading (Calkins et al., 2015). The mathematics curriculum taught was Everyday Mathematics (The University of Chicago School Mathematics Project, 2003).

Team 2. The school in which the second PLC teacher team (Team 2) operated was a K-5 school with a separate teacher team meeting for each grade level. The $4^{\text {th }}$ grade teachers were the participants for the current study. There were 480 students enrolled in this school, $28.1 \%$ of whom were eligible for the FRPL program and $8.6 \%$ received special education services. A plurality of students in this school were Caucasian (70.2\%), 11.7\% were African-American, 8.3\% Multiple races, $5 \%$ Hispanic, $4.4 \%$ Asian-American, and $0.4 \%$ were Native-American. A total of 82 students were enrolled in the $4^{\text {th }}$ grade. The Team 2 members included the four fourth grade teachers in the school, all of which attended the weekly team meetings regularly. The team 
meeting occurred once per week during lunch and the team discussed lesson plans for the week, curriculum, and activities with students. Meetings were held in a teacher's classroom and lasted between 40 and 50 minutes. Team 2 met additionally once per week to discuss only student literacy and mathematics data and problem solving, a meeting they referred to as the Data Team Meeting. The members of Team 2 consisted of four Caucasian females, one had obtained a Bachelors degree and three had obtained Masters degrees. Team 2 teachers had an average of 6.8 years of teaching experience and an average of 4.5 years of experience in teaching the current grade. Team 2 taught the Good Habits, Great Readers (Klein et al., 2012) reading curriculum and EnVisions Math (enVision Math Common Core, 2012) mathematics curriculum.

Team 3. The school in which the third PLC teacher team (Team 3) operated within a K-5 school with a separate teacher team meeting for each grade level. The $4^{\text {th }}$ grade teachers were the participants for the current study. There were 448 students enrolled in this school, $70.1 \%$ of whom were eligible for the FRPL program and $13.4 \%$ received special education services. The school consisted of a diverse student population with $37.5 \%$ of the students being Caucasian, $36.4 \%$ were African-American, 10.5\% Hispanic, 8.5\% Asian-American, 5.8\% Multiple races, $0.9 \%$ Pacific-Islander, and $0.5 \%$ Native-American. A total of 84 students were enrolled in the $4^{\text {th }}$ grade.

The Team 3 members included the four $4^{\text {th }}$ grade teachers in the school, all of which attended the weekly team meetings regularly. The media specialist attended five meetings and the principal attended three meetings. The team meeting occurred once per week during their morning planning period and the team discussed lesson plans for the week, curriculum, and activities with students. Meetings were held in one of the $4^{\text {th }}$ grade teacher's classrooms and lasted between 40 and 50 minutes. The members of Team 3 consisted of four Caucasian females, 
all of whom had obtained a Masters degree. Team 3 teachers had an average of 4 years of teaching experience and an average of 2.8 years of experience in teaching the current grade. Team 3 taught the Good Habits, Great Readers (Klein et al., 2012) reading curriculum. Two of the teachers used the EnVisions Math (enVision Math Common Core, 2012) mathematics curriculum. The other two teachers used Everyday Math (The University of Chicago School Mathematics Project, 2003) for their curriculum as a pilot for the district.

Team 4. Finally, the fourth team (Team 4) was within a K-5 school the utilized an Individually Guided Education approach to grade-level assignments. The school was organized into three learning communities, or units, across the grade levels. A total of 237 students attended the school, $15.6 \%$ of which were eligible for FRPL and 5.4\% received special education services. The student population was majority Caucasian (74.3\%), 9.7\% Multiple races, 7.6\% African-American, 5.9\% Asian-American, and 2.3\% Hispanic. Unit C, or $4^{\text {th }}$ and $5^{\text {th }}$ grades, consisted of 70 students. The Team 4 members were the teachers providing instruction to students in Unit C, all of which attended the meeting regularly. Neither the principal nor any other school personnel attended the meetings. Team 4 met regularly three times per week to discuss lesson planning, scheduling, and various student or classroom activities. The meetings were held a table outside all three of the classrooms and lasted between 45 minutes to 1 hour. Team 4 was observed during one of their weekly team meetings. The members of Team 4 consisted of two Caucasian females and one Hispanic female. Two teachers were finishing their Masters education and one teacher had obtained a Juris Doctorate degree. Team 4 teachers had an average of 14 years of teaching experience and an average of 7.3 years of experience in teaching the current grade. Team 4 taught the Good Habits, Great Readers (Klein et al., 2012) 
reading curriculum and EnVisions Math (enVision Math Common Core, 2012) mathematics curriculum.

The schools for Teams 2 and 3 were participating in year 1 of implementation of the Missouri PLC Project. The Missouri PLC Project was developed to provide training, support, and resources to schools implementing PLCs. Leadership teams from schools within the first year of the project attend trainings encompassing the following topics: foundations of PLCs, collaboration norms, shared leadership, teaming practices, essential learning objectives, assessment, and introduction to the PLC Implementation Rubric. During year 1 of the project, PLC implementation is at the building level and grade-level PLC teams are not yet established. The teachers of Teams 2 and 3 were aware of the school's participation in the Missouri PLC project, but were not directly utilizing PLC principles in their team meetings (DESE, 2014).

\section{Measure}

One measure was used to address the research questions; a rubric adapted to assess each PLC in the participating schools. The measure is described below.

PLC Implementation Rubric. The implementation of PLCs within Missouri schools was measured through an implementation rubric (PLC Implementation Rubric) that was designed to be used by PLC teams to self-assess their implementation formatively, and by PLC consultants as a summative assessment for each school (DESE, 2014). The rubric contains eight strands that are rated as Deep, Proficient, Partial, or Minimal (DESE, 2014). Four to seven items comprise each strand, for a total of 46 indicators within the rubric. The reliability coefficient for the entire scale was .98 , with reliability coefficients for each strand above .85 (Burns et al., in press). Eight strands represented the attributes of effective PLCs as described in the literature (DuFour et al., 1998; Hord, 1997). Examples are provided on the rubric at each of the 
implementation levels (i.e., Deep, Proficient, Partial, and Minimal) to support scoring. Following an exploratory factor analysis, the items of the PLC Implementation Rubric were found to load onto two factors, Collaborative Leadership Processes and Data-Driven Systems of Learning (Burns et al., in press).

The current study adapted the PLC Implementation Rubric to only include those items within strands that can be observed during the regular PLC team meetings. Specifically, the Trust/Participation item from Strand 4 was removed as it was considered to be not easily observed during weekly meetings. All other items on the strands were kept in tact. The observation tool was composed of the listed adapted strands: Strand \#4 How Effective Teams Work $(\alpha=.90)$, Strand \#5 What Students Need to Know and Do $(\alpha=.91)$, and Strand \#6 Assessment for/of Learning ( $\alpha=.86$ ) (Burns et al., in press). The specific items included in the

three strands are listed in Table 1. Data for the study consisted of the observed implementation of each item within the three strands.

\section{Intervention}

The consultation protocol used was adapted from Rosenfield and Gravois (1996), and Rosenfield (2014). Within this model, the researcher consulted with the PLC during their meetings and worked with them on the following activities: (a) defining the need(s) of the team, (b) examining classroom data, (c) brainstorming teacher interventions, (d) implementing teacher interventions, (e) problem solving any unforeseen difficulties, and (f) discussing how the team will monitor their progress. During the first intervention session, the researcher went over the baseline data with the PLC and identified areas of strength and areas for growth. The researcher guided the PLC through identifying one or two specific areas on which to focus and develop goals to address those areas. The specifics regarding data collection to monitor progress and how 
the goal(s) developed by the PLC were addressed and were developed by the PLC, with the help of the researcher. During subsequent intervention sessions, the researcher followed-up with the PLC on current progress towards the goal(s) using the protocol activities listed above.

Baseline. Prior to the beginning of the baseline phase, the researcher met with each team and explained the project to the teachers. Then each teacher signed the consent for participation in the current study. The researcher observed the team using the PLC Implementation Rubric. During the baseline phase, the researcher did not provide any comment or consultation, the team was observed silently. Each meeting, for each team, the researcher observed the team during their weekly meeting time and completed the PLC Implementation Rubric to obtain baseline implementation scores.

Intervention. When the baseline data were collected, the researcher provided the team with bar graphs of the data from the implementation rubric. The researcher talked with the team about the data shown on the graphs, asked them to identify areas of strength and weakness. When the teachers identified the areas of weakness, the researcher asked the team to respond to the identified areas of weakness. Then the researcher asked the teachers to prioritize the area of weakness they would like to address. For multiple teams, the teachers were given 1 week to consider the data and discuss among themselves. During the team meeting the following week, the researcher asked the teachers again their thoughts on the areas of weakness and ideas for next steps. The researcher provided ideas of strategies other teams utilized and the teachers selected an intervention to implement. The researcher then talked the teachers through the intervention and together they developed the goal and how the intervention was to be implemented. During the team meetings following the goal and intervention determination, the researcher strove to address the goal with the team and provide support to any barriers, if necessary. On the sixth 
intervention meeting, the researcher explained that the consultation was being terminated and went through the following actions, (a) reviewed the goal from the self-identified problem, (b) updated the team on progress towards the goal, and (c) brainstormed next steps with the team and how they may continue working towards the goal. It was also explained to the team that observers would continue to observe the meetings for the following 3 weeks.

Maintenance. Observers continued observing the weekly team meetings for the following 3 weeks. The observers did not provide any consultation and observed the team proceedings in silence while completing the PLC Implementation Rubric.

\section{Procedure}

The PLC team was observed once a week, during their regularly scheduled PLC meeting time. The observer used the adapted PLC observation form to assess the implementation of the PLC principles during the meeting. During the baseline period, the observer only observed the team using the previously described form. After adequate baseline data were collected, the researcher consulted with the team using the six steps listed previously. An observer continued to observe the team's PLC implementation while the researcher provided consultation during the same meeting times. During intervention implementation, the researcher cannot observe the PLC team and provide consultation at the same time. Therefore, observers were trained to use the PLC observation tool by the first author.

\section{Interobserver agreement}

The observers for the study were school psychology graduate students. Each student had advanced training in behavioral observation techniques and data collection. The observers received an addition 1 hour of individual training from the author in the PLC Implementation Rubric. Next, each observer and the first author observed a previously video-recorded PLC 
meeting together to assure reliable observation. The number of items the both observers rated consistently as observed or not observed was divided by the total number of items on the observation form. There was an average of $87 \%$ agreement between observers and the first author. Discussions regarding observations were held between the first author and observers to reduce future disagreements.

Agreement checks between two observers were conducted for approximately $25 \%$ of the total observations across the four teams throughout the course of the study. The resulting agreement ranged from $72 \%$ to $100 \%$ and an average agreement of $89 \%$. Interobserver agreement was also calculated for each of the three strands with an average agreement of $89 \%$ for Strand 4, 89\% for Strand 5, and 90\% for Strand 6.

\section{Treatment integrity}

An intervention integrity checklist was created for the consultation interventions. The observer evaluating the PLC team also observed the researcher and rated consultation treatment fidelity. The consultation treatment integrity was observed and rated during $25 \%$ of the intervention sessions. The number of observed items from the checklist was divided by the total number of items and multiplied by 100 . The average treatment integrity rating was $73 \%$ for the sessions. Treatment integrity in previous instructional consultation studies ranges from $80-100 \%$, however, the consultation procedures in those studies were measured through an interview of consultees and not directly observed, as in the current study (Kaiser et al., 2009; Vu et al., 2013)

\section{Experimental design}

The current study's design replicated Burns, Peters, and Noell (2008), and used a multiple-baseline design across PLCs. Each PLC meeting was observed by a researcher using the aforementioned checklist. Baseline data were collected for each PLC before researcher 
consultation was implemented. During the intervention phase, the researcher consulted on databased decision making regarding students as discussed during the PLC meeting.

Due to the use of a multiple baseline design, the PLC team in entirety is the unit of analysis. The onset of data collection and implementation for each team was in the order of which the team agreed to participate in the study. The amount of baseline collected ranged from four to seven points to ensure staggered implementation. A total of six intervention data points were collected for each team. When the intervention was implemented, the researcher consulted on the team needs and processes. When intervention implementation was completed, three maintenance data points were collected for each team. Throughout the research project, the PLC implementation, as observed using the PLC Implementation Rubric, served as the primary dependent variable to measure PLC implementation.

Analysis. Visual analysis of the graphed data collected was conducted to determine the presence of a relationship and the strength of the relationship between an independent variable and a dependent variable (Riley-Tillman \& Burns, 2010). In order to evaluate the intervention effects of consultation, observation data was visually inspected for change in level, trend, and variability.

Percent of Nonoverlapping Data (PND) were also computed to estimate change in level for intervention for the average total implementation and the average implementation on Strand 4. PND was calculated by identifying the most extreme baseline data point for each team and drawing a straight line across that data point. The number of intervention data points that were above the line was divided by the total intervention data points to determine PND (Scruggs, Mastropieri, \& Casto, 1987). Standards suggest that a large effect is represented by a PND of $80 \%$ or higher (Scruggs \& Mastropieri, 1998). 
Slope was calculated for each graph to determine trend. Slope is calculated by computing the change in $y$-axis data points divided by the change in $\mathrm{x}$-axis data points for the baseline, intervention, and maintenance phases, respectively. A positive trend is a slope of greater than 0 . A negative trend is a slope of less than 0 . A flat trend is a slope very close to or equal to 0 .

Effect size was calculated for each team's total average implementation using Nonoverlap of all pairs (NAP). NAP was computed by determining the frequency of overlap between the baseline and intervention data points (Parker \& Vannest, 2009). More specifically, each pair of baseline and intervention data points were coded based upon overlap; baseline exceeded the intervention (1), pair was equal (.5), or did not overlap (0). NAP was then converted to a phi coefficient to obtain an effect size (Ruscio, 2008). Based upon meta analyses from Parker and colleagues (2011), phi coefficients of .49 were considered small, .72 were medium, and .83 or larger were large. NAP provides an accurate and efficient measure of effect size for single-case design studies (Parker \& Vannest, 2009). 


\section{CHAPTER IV: RESULTS}

This chapter focuses on the research question and results of this study. The study address the following research question: What is the effect of consultation with teachers on the implementation fidelity of professional learning communities? Each team chose to focus on one item from the How Effective Teams Work strand (Strand 4) of the PLC Implementation Rubric. The PLC implementation of each team was measured for both Strand 4 and the total of the three strands observed. The results of each for each team are discussed respectively.

\section{Implementation across all Strands}

Results of each team's total implementation for all three strands are presented in Figure 1 and Table 1. The sum of the average implementation scores for each strand is shown in Figure 1. The mean and standard deviation for the baseline, intervention, and maintenance phases, as well as, the NAP for each team and for the total implementation for all three strands are displayed in Table 1.

Team 1. Team 1's total average performance on PLC implementation for all three strands before, during, and after consultation is shown in Figure 1 and Table 1. PLC implementation during baseline was stable for Team 1. A slight increase is observed at the initial start of the intervention phase, followed by some decrease. However, Team 1 increased their PLC practices above that of baseline during the last 3 weeks of intervention. Team 1's implementation drastically improved at the start of the maintenance phase, then implementation decreased to a level commiserate to the intervention phase. During baseline, Team 1 never exceeded a total average score of 2 with a mean of $0.54(S D=0.76)$ and slope of 0.02 . The overall level of implementation in the intervention phase improved from baseline with a mean of $0.87(S D=$ 0.88 ) and a negligible change in slope to 0.06 . The percent of non-overlapping data from 
baseline to intervention was $67 \%$. The phi coefficient was 0.43 , which indicates a small effect size. Team 1's lowest score in maintenance was higher than the highest score in baseline. During maintenance, Team 1 displayed a mean of $1.61(S D=1.20)$ and a negative slope of -0.67 .

Team 2. Team 2's total average performance on PLC implementation for all three strands before, during, and after consultation is shown in Figure 1 and Table 1. Team 2's implementation during baseline decreased, but was relatively stable throughout the phase. Team 2 exhibited similar PLC practices and responses to intervention and maintenance as Team 1, but to a lesser degree of implementation. At the start of the intervention phase, there was little to no change in implementation until the third week of consultation when there was an increase in implementation followed by a slower decrease. Team 2 increased implementation at the start of the maintenance, decreasing implementation as the phase continued. Team 2 never exceeded a total average implementation score of 1.6 during baseline. The average implementation during baseline for Team 2 was $0.34(S D=0.56)$, with a slope of -0.27 . During the intervention phase, both the overall level of implementation fidelity and rate of growth improved, showing a steeper positive slope (i.e., 0.17$)$ and higher mean of implementation of $0.46(S D=0.77)$. The percent of non-overlapping data from baseline to intervention was $17 \%$. The phi coefficient was 0.14 , which indicates a negligible effect size. During maintenance, Team 2 displayed a mean of 0.71 $(S D=1.06)$ and a decreased slope of -1.13 .

Team 3. Team 3's total average performance on PLC implementation for all three strands before, during, and after consultation is shown in Figure 1 and Table 1. Team 3's implementation during baseline decreased from the start of the phase with a slight increase followed by another decrease. Team 3 considerably improved PLC implementation at the start of the intervention and varied their implementation throughout the phase. Team 3 began maintenance similarly to where 
the intervention phase ended and did improve implementation before dropping below a score of 2. Baseline implementation for Team 3 started higher than that of Teams 1 and 2, but did decrease to a score of 0.5 at the end of the phase. The average implementation for Team 3 during baseline was $0.39(S D=0.65)$ with a slope of -0.23 . During the intervention phase, the overall level of implementation fidelity improved, with a mean of implementation of $0.81(S D=1.00)$. The slope during intervention did not improve (i.e., -0.23). The percent of non-overlapping data from baseline to intervention was $67 \%$. The phi coefficient was 0.53 , which indicates a small effect size. During maintenance, Team 3 displayed a mean of $0.88(S D=1.24)$ and a negative slope of -0.49 .

Team 4. Team 4's total average performance on PLC implementation for all three strands before, during, and after consultation is shown in Figure 1 and Table 1. Team 4 displayed the least change across the three phases, when compared to the other three teams. Implementation during baseline for Team 4 was stable with only slight changes in implementation. Team 4's implementation did improve during intervention. Lastly, implementation during maintenance was commiserate with the intervention phase. Team 4's implementation during baseline never obtained a total average implementation score above 0.92 with a mean of $0.26(S D=0.62)$ and slope of 0.03 . During the intervention phase, the overall level of implementation fidelity improved minimally to $0.48(S D=1.12)$. The slope during intervention decreased to -0.06 . The percent of non-overlapping data from baseline to intervention was $100 \%$. The phi coefficient was 0.99, which indicates a large effect size. During maintenance, Team 4 displayed a mean of 0.53 $(S D=1.19)$ and a slope of -0.19 .

Overall. The implementation of PLC practices for each team was low during baseline. All four teams displayed an increased improvement in their total implementation during the $3^{\text {rd }}$ 
or $4^{\text {th }}$ week of intervention. It is also important to note that while each team displayed a negative slope during maintenance, the highest total average implementation score for three out of the four teams occurred during the maintenance phase. During baseline, the mean implementation of the four teams was $0.37(S D=0.65)$, with a range of 0.26 to 0.54 for each team. The mean increased during intervention to $0.66(S D=0.97)$, with a range of 0.46 to 0.87 for each team. The percent of non-overlapping data from baseline to intervention was $82 \%$. The phi coefficient was 0.54, which indicates a small effect size. During maintenance, the implementation mean continued to improve, $0.93(S D=1.24)$, with a range of 0.53 to 1.61 for each team.

Table 1

Means and Standard Deviations of the Total Sum Average Implementation Scores across three Strands and Effect Sizes

\begin{tabular}{lcccccccc}
\hline & \multicolumn{2}{c}{ Baseline } & \multicolumn{2}{c}{ Intervention } & \multicolumn{2}{c}{ Maintenance } & & \\
& $\mathrm{M}$ & $\mathrm{SD}$ & $\mathrm{M}$ & $\mathrm{SD}$ & $\mathrm{M}$ & $\mathrm{SD}$ & $\mathrm{NAP} *$ & Phi \\
\hline Team 1 & 0.54 & 0.76 & 0.87 & 0.88 & 1.61 & 1.20 & 0.75 & 0.43 \\
Team 2 & 0.34 & 0.56 & 0.46 & 0.77 & 0.71 & 1.06 & 0.58 & 0.14 \\
Team 3 & 0.39 & 0.65 & 0.81 & 1.00 & 0.88 & 1.24 & 0.81 & 0.53 \\
Team 4 & 0.26 & 0.62 & 0.48 & 1.12 & 0.53 & 1.19 & 1.00 & 0.99 \\
Total & 0.37 & 0.65 & 0.66 & 0.97 & 0.93 & 1.24 & 0.82 & 0.54
\end{tabular}

*Non-overlap of all pairs (NAP) compares intervention phase data to baseline phase data. 
Figure 1

Total Sum Average Implementation Scores across three Strands

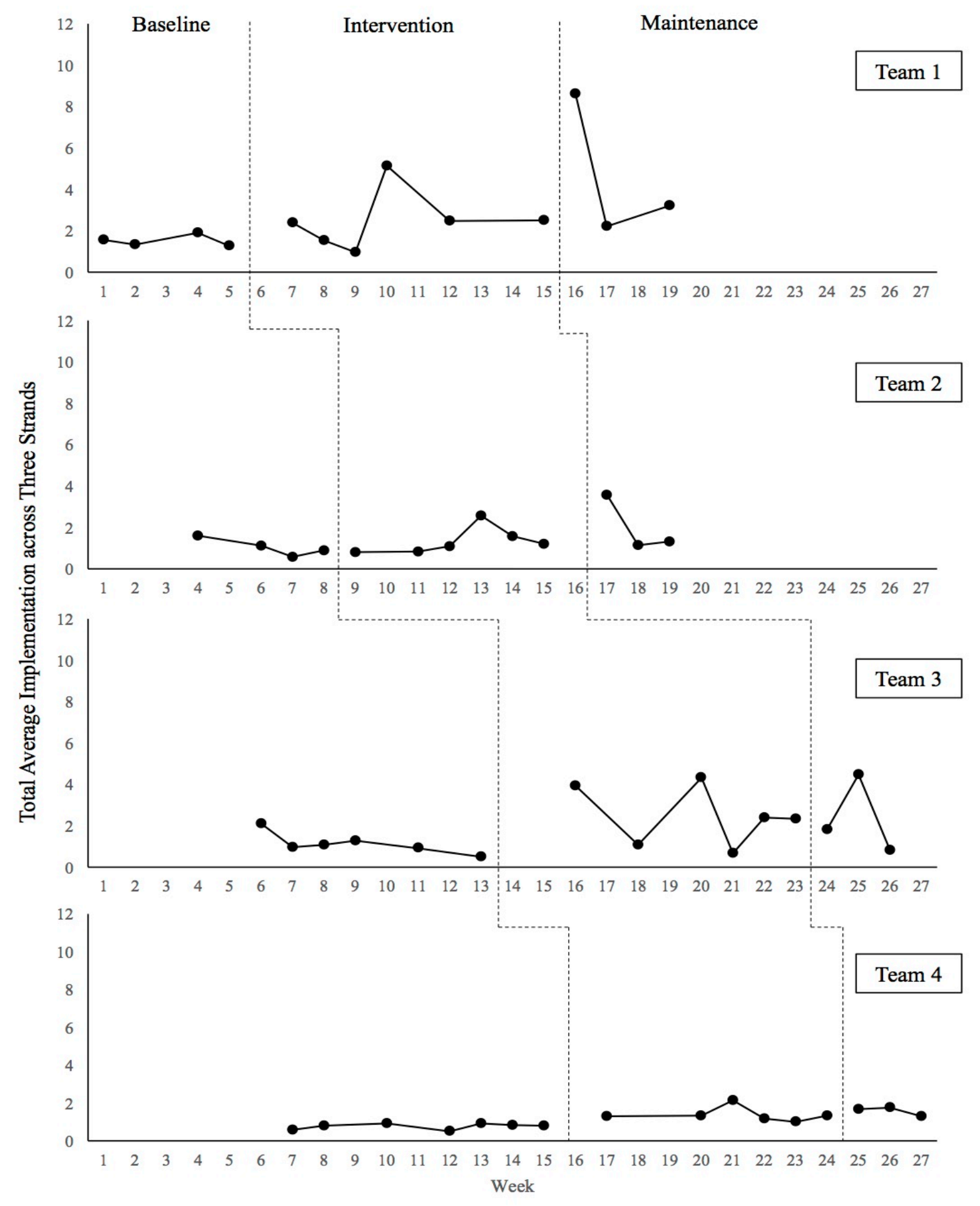




\section{Strand 4: How Effective Teams Work}

Results of each team's implementation fidelity of Strand 4 are presented in Figure 2 and Table 2. The average implementation score on Strand 4 for each week is shown in Figure 2. The mean and standard deviation for the baseline, intervention, and maintenance phases, as well as, the NAP for each team and for the total implementation for Strand 4 are shown in Table 2.

Team 1. Team 1's performance on PLC implementation fidelity for Strand 4 before, during, and after consultation are displayed in Figure 2 and Table 2. Team 1's implementation during baseline decreased from the initial start of the phase, but increased back to level of the initial start. Team 1 never exceeded an average score of 1 during baseline, but did increase in level during intervention. Team 1 also maintained their implementation from the intervention phase through the maintenance phase. Team 1's average implementation during baseline was $0.79(S D=0.88)$ with a slope of -0.02 . Implementation improved to a mean of $1.42(S D=0.81)$ during intervention, with a slope of -0.01 . The percent of non-overlapping data between baseline and intervention was $83 \%$. The phi coefficient was 0.59 , which indicates a small effect size. During maintenance, Team 1 displayed a mean of $1.89(S D=1.18)$ and a slope of -0.67 .

Team 2. Team 2's performance on PLC implementation fidelity for Strand 4 before, during, and after consultation are displayed in Figure 2 and Table 2. Team 2's implementation during baseline decreased slightly after the initial start of the phase, but did increase back to the level at the start. During intervention and then maintenance, Team 2's implementation steadily trended upwards, displaying a positive effect. Team 2 did not exceed an average implementation data point of 0.67 during baseline, with a mean of $0.46(S D=0.72)$ and a slope of -0.05 . During the intervention phase, both the overall level of implementation fidelity and rate of growth improved, with a steeper positive slope (i.e., 0.08) and higher mean of implementation of 1.00 
$(S D=0.93)$. The percent of non-overlapping data from baseline to intervention was $83 \%$. The phi coefficient was 0.82 , which indicates a moderate effect size. Team 2 displayed a mean of $1.22(S D=1.22)$ and a decreased slope of 0 during the maintenance phase.

Team 3. Team 3's performance on PLC implementation fidelity for Strand 4 before, during, and after consultation are displayed in Figure 2 and Table 2. PLC implementation during baseline remained stable throughout the phase. Implementation during the intervention phase improved drastically from baseline, despite the variability within the phase. Team 3's practices improved overall even more during the maintenance phase, despite a decrease in implementation at the end of the phase. The mean implementation during baseline was $0.56(S D=0.81)$ with a slope of 0 . During intervention, only two out of the six data points fell below an average score of 1. The mean implementation during intervention improved to $1.22(S D=1.17)$, with a negligible change in slope to 0.05 . The percent of non-overlapping data from baseline to intervention was $83 \%$. The phi coefficient was 0.80 , which indicates a moderate effect size. During maintenance, Team 3 displayed a mean of $1.61(S D=1.38)$ and a negative slope of -0.42 .

Team 4. Team 4's performance on PLC implementation fidelity for Strand 4 before, during, and after consultation are displayed in Figure 2 and Table 2. Team 4's PLC implementation showed some improvement during the baseline phase. Team 4's implementation during intervention increased a level from baseline. Team 4's implementation during maintenance was similar to that during intervention, indicating the level of PLC implementation can be maintained in the absence of the consultant. The mean for the baseline phase was 0.62 $(S D=0.88)$ with a slope of 0.05 . During the intervention phase, the overall level of implementation improved to $1.25(S D=1.59)$, with a decreased slope of -0.01 . Although there is a decrease in slope, the percent of non-overlapping data from baseline to intervention was $100 \%$. 
The phi coefficient was 0.99 , which indicates a large effect size. During maintenance, Team 4 displayed a mean of $1.33(S D=1.68)$ and an improved slope of 0.07 .

Overall. The implementation of PLC practices for each team was low during baseline and never exceeded an average score of 1 . All four teams began the intervention phase with a higher implementation score than the last baseline implementation score. It is also important to note that the lowest data point for each team during maintenance was higher than the lowest data point for each team during intervention. During baseline, the mean implementation of the four teams was $0.60(S D=0.83)$, with a range of 0.46 to 0.79 for each team. The mean increased during intervention to $1.22(S D=1.16)$, with a range of 1.00 to 1.42 for each team. The percent of non-overlapping data from baseline to intervention was $96 \%$. The phi coefficient was 0.78 , which indicates a moderate effect size. During maintenance, the implementation mean continued to improve, $M=1.51(S D=1.37)$, with a range of 1.22 to 1.89 for each team.

Table 2

Means and Standard Deviations of the Total Sum Average Implementation Scores across Strand 4 and Effect Sizes

\begin{tabular}{lcccccccc}
\hline & \multicolumn{2}{c}{ Baseline } & \multicolumn{2}{c}{ Intervention } & \multicolumn{2}{c}{ Maintenance } & & \\
& $\mathrm{M}$ & $\mathrm{SD}$ & $\mathrm{M}$ & $\mathrm{SD}$ & $\mathrm{M}$ & $\mathrm{SD}$ & $\mathrm{NAP*}$ & Phi \\
\hline Team 1 & 0.79 & 0.88 & 1.42 & 0.81 & 1.89 & 1.18 & 0.85 & 0.59 \\
Team 2 & 0.46 & 0.72 & 1.00 & 0.93 & 1.22 & 1.22 & 0.98 & 0.82 \\
Team 3 & 0.56 & 0.81 & 1.22 & 1.17 & 1.61 & 1.38 & 0.97 & 0.80 \\
Team 4 & 0.62 & 0.88 & 1.25 & 1.59 & 1.33 & 1.68 & 1.00 & 0.99 \\
Total & 0.60 & 0.83 & 1.22 & 1.16 & 1.51 & 1.37 & 0.96 & 0.78 \\
\hline *Non-overlap of all pairs (NAP) compares intervention phase data to baseline phase data
\end{tabular}

*Non-overlap of all pairs (NAP) compares intervention phase data to baseline phase data. 
Figure 2

Total Sum Average Implementation Scores across Strand 4

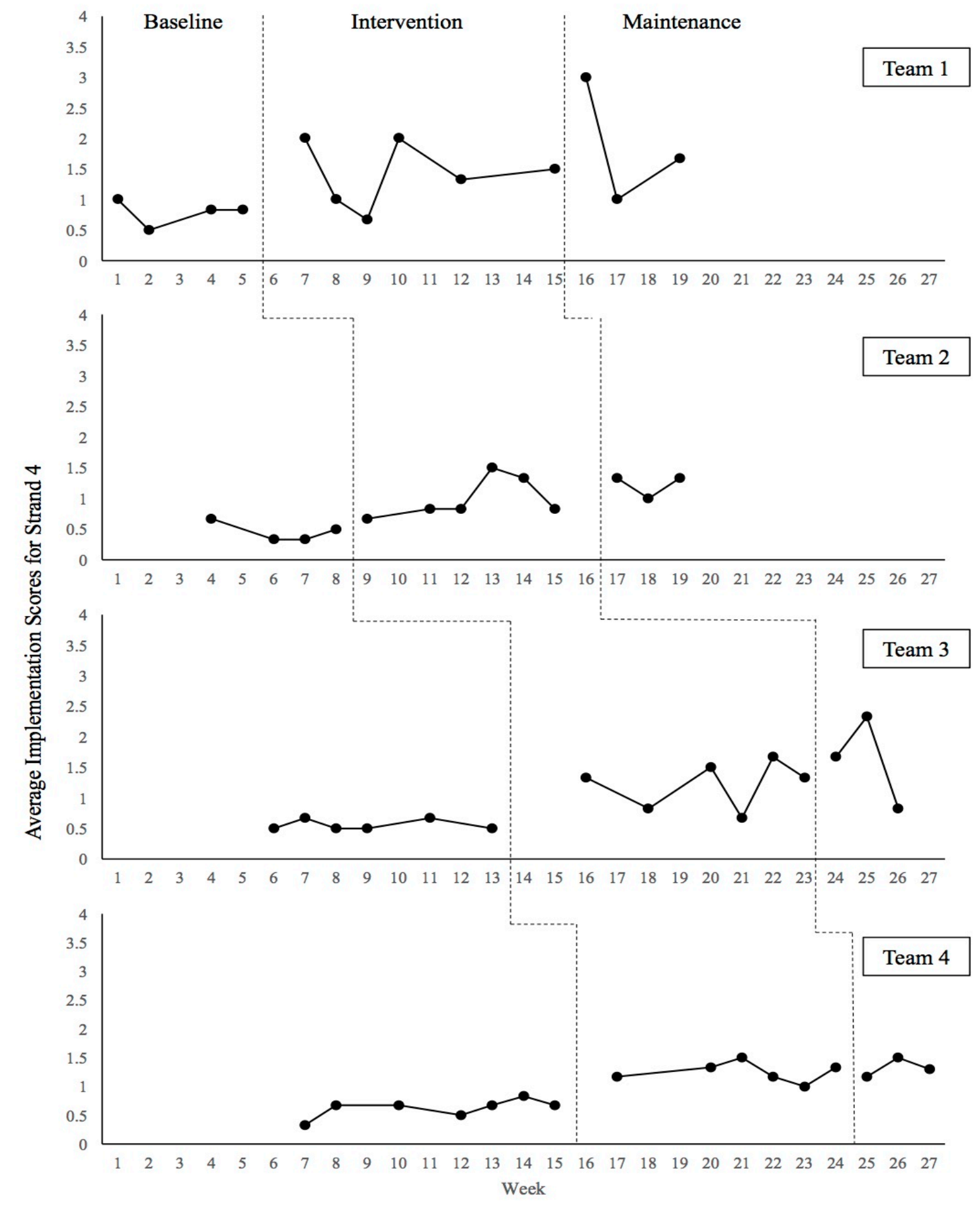




\section{CHAPTER V: DISCUSSION}

The current study expanded existing professional learning community (PLC) literature to include the effects of consultation on implementation of PLCs. The study addressed the following research question: What is the effect of consultation with teachers on the implementation fidelity of professional learning communities? It was hypothesized that the PLC teams would improve their implementation of PLC practices when provided consultation and observed using the PLC Implementation Rubric. There was an improvement during the intervention phase for all four PLC teams.

The results from the study indicated a change in PLC implementation occurred when consultation started, but the effect for the total strand score was negligible to small. Each team displayed an improvement in their implementation of PLC practices that was maintained after consultation ended. However, the improvements for each team during the intervention and maintenance phases were small, in comparison to the baseline phase. Each team chose to focus on an item from Strand 4: How Effective Teams Work. Therefore, increased improvements were noted for Strand 4, with a moderate effect.

As stated previously, each team improved their PLC implementation during intervention and those improvements were maintained during maintenance. For the three stands taken together, three out of the four teams obtained their highest implementation data point during the maintenance phase. On the three strands, Team 2 exhibited a negligible effect size, Teams 1 and 3 small effect sizes, Team 4 large effect size, and overall team score small effect size. On Strand 4 alone, Team 1 exhibited a small effect size, Teams 2 and 3 moderate effect size, Team 4 large effect size, and overall team score moderate effect size. The variability of means and effect sizes 
between the total of the three strands and Strand 4 indicate that improved implementation for one PLC area does not easily influence performance in other PLC areas.

The data from the current study suggest a relationship between the intervention and PLC implementation, especially for Strand 4. However, the effects were small. There were several potential reasons why the effects were small.

First, teachers rarely discussed data and its relationship to teacher practices during the meetings, an important component to PLC practices. Research indicates that teachers dislike focusing on and discussing data, leading to poor PLC implementation (Sims \& Penny, 2015). Second, the format of the PLC model in each school varied and could have contributed to the small effects noted here. For example, two of the teams reported that they discussed students and learning throughout the school week and not just during their regularly scheduled weekly teacher team meeting. Moreover, the building principal only occasionally participated in the team meetings for two teams and did not participate at all for two teams. Third, there could have been inconsistent understanding of a PLC across teams. Two of the teams reported that they did not identify themselves as PLCs, even both selected to participate in the study and one was participating in the first year of the Missouri PLC implementation.

\section{Previous Research on PLC Implementation}

The overall purpose of PLCs is to change educator behavior through collaborative engagement with colleagues (DuFour, Eaker, \& DuFour, 2005). However, school teams do not often follow implementation guidelines (Burns \& Symington, 2002). The consultation literature base continues to expand; however, much of the literature base consists of commentaries and frameworks. Little empirical research examines specific consultative procedures and the implementation integrity of those procedures (Noell \& Gansle, 2014). Subsequently, research has 
yet to adequately examine the complexity of treatment integrity within consultation, i.e., the implementation integrity of the consultative process by the consultant and/or the implementation integrity of the intervention by the consultee. While the average treatment integrity for the current study was $73 \%$, previous studies have indicated some positive outcomes despite imperfect implementation (Gansle \& McMahon, 1997; Holcombe, Wolery, \& Snyder, 1994; Vollmer, Roane, Ringdahl, \& Marcus, 1999). Research is needed expand consultation research by examining treatment integrity of specific consultative procedures and by investigating the implementation integrity of consultee delivered interventions.

Inconsistent implementation. Previous research has demonstrated that educational teams are plagued by inconsistent implementation practices (Buck et al., 2003). However, the addition of consultation with school teams has increased implementation fidelity of team processes and interventions (Burns et al., 2008; Noell et al., 1997). Additionally, intervention integrity improves when consultation and performance feedback are provided to teams, especially problem-solving teams (Burns et al., 2008). Consistent with previous research, the variability of PLC practices across schools in the current study was evident in the variability of responses to consultation, despite the lack of variability in the consultation provided to each team.

Poor implementation of PLCs. When PLCs are implemented with integrity, they could have potential to lead to better school decisions and subsequently better student outcomes. Little empirical research exists examining the effectiveness of PLCs. In Iceland, a moderate relationship was exhibited between PLC effectiveness and teacher perception in addition to improved student mathematics achievement (Sigurðardóttir, 2010). A positive relationship existed between academic performance with authentic learning and professional community 
(Louis \& Marks, 1998). Student behavioral difficulties decrease with the implementation of a PLC model (Andrews \& Louis, 2007). This study did not examine student outcomes, which suggests an area for future research, but the magnitude of change in implementation would seem unlikely to result in a change in student learning. Consistent with Sims and Penny (2015), in which improvements in student achievement were not observed in either the classroom or on high-stakes tests following ineffective implementation of PLC processes.

Consultation with problem-solving processes. The influence of consultation on PLC implementation has yet to be examined within research. Consultation is effective in itself, but has yet to be examined with regards to regular teacher meetings. Previous research provided consultation to teachers in their problem-solving processes and intervention implementation (Truscott et al., 2000; Lane et al., 2003). Teachers have reported satisfaction with instructional consultation models and this satisfaction as significantly related to the teacher perceptions of student outcomes (Kaiser et al., 2009). Teachers collaborating with instructional consultation teams were more effective and more collaborative than teachers without consultation (Vu et al., 2013). While teachers are reporting higher levels of satisfaction, efficacy, and collaboration with instructional consultation methods, student outcomes were not reported. Elements of consultation, such as performance feedback, are considered evidence-based practices (Fallon, Collier-Meek, Maggin, Sanetti, \& Johnson, 2015), however, consultation research rarely examines student outcomes. Consistent with the previous research, the current study focused on the PLC practices of the team and not student outcomes (Lane et al., 2003). The lack of reported student outcomes indicates a need for emphasizing student data, especially as the goals of instructional consultation are to improve student achievement and performance. Future research efforts should examine the effects of consultation on student outcomes. Specifically, research 
could determine if consultation on instructional practices influences academic and behavioral outcomes at the classroom level.

\section{Implications for Practice}

School psychologists are uniquely trained to not only assess the needs of students, but to also consult with teachers and educational professionals on individual, classroom, and systems levels. However, only $41 \%$ of California school psychologists surveyed indicated that they regularly participated in teacher consultation (Powers et al., 2008). The results of a megaanalysis on school psychology practice domains (Burns et al., 2013) suggests that school psychologists can be effective in influencing school decisions and practices across universal, classroom, and individual levels. Specifically, small to medium effect sizes were demonstrated for school psychological services at Tier $1(d=0.34)$ and Tier $2(d=0.38)$, indicating the potential for school psychologists to influence practices at those tiers. Thus, school psychologists could expand their daily practice to include consultation methods at the universal and targeted levels and influence academic and behavioral outcomes for students. Results from the current study demonstrate the moderate effect of consultation on a specific practice, but not on the overall process. Specifically, larger effects were observed on Strand 4 practices than on the three strands taken together. Even though the teams each focused on an item from Strand 4, it was the hope that the team's efforts to improve the item on Strand 4 would also extend to practices corresponding to the other strands. However, this was not the case in the current study, suggesting that focusing on a singular item will improve that item, but may not improve other areas. Thus, consultation efforts should be specific to the needs of the team and maintain a clear focus throughout the consultation process. Future research is needed to further this line of inquiry by studying multiple components of consultation sequentially. 
As school psychology continues to move into the $21^{\text {st }}$ century, practitioners still struggle with addressing big problems in education. By utilizing a systems consultation approach, practitioners are able to not only address the needs of many students, but also address big issues in education (Shapiro, 2000). The current study suggests a framework for school psychologists to implement a more systems focused approach by addressing teacher instructional practices through a PLC framework. School psychologists are provided an outline for how to address instructional practices with the PLC framework since PLC practices require teachers to collaborate on their classroom data and instruction. Additionally, instructional consultation methods can be adapted for use with team meetings, as demonstrated by the current study. School psychologists can use instructional consultation methodology or the problem-solving model to identify a clear focus for the team consultation.

\section{Theoretical Implications}

Findings from the current study yield potentially important implications for theory. The current study used instructional consultation methodology (Rosenfield, 2002) with the team as the unit of analysis instead of individual students. The current data support the use of instructional consultation in this manner, however, more research is needed. The current data further supports the reasoning that inconsistent implementation will result in decreased improvements (Burns et al., 2008; Noell et al., 1997). Future research could examine the influence of consultation with PLCs at the same phase of implementation, which would allow for a comparison with less assumed variability.

\section{Limitations}


Several limitations to the current study warrant consideration and highlight the need for more research in changing PLC implementation. The limitations to the current study are described below.

First, two of the schools were currently involved in the Missouri PLC Essential Curriculum and two of the schools were not. Therefore, there was inconsistent understanding of the roles of functions of a PLC. Second, there appeared to be inconsistent administrator support for PLC practices across schools. Administrator support is critical to effective school-based team implementation (Burns, Kanive, \& Karich, 2014). The principal regularly attended meetings for two schools, but did not attend for two school. The level of support outside of the meetings was unknown. All of the principals expressed an interest in supporting teacher team meetings during the recruitment phase of the study, but principal interest or support was not gauged at any other time point. Third, teachers may have collaborated in different meetings throughout the week, and the effect on implementation was unknown. Moreover, there may have been different meetings in which aspects of PLC implementation occurred and could have been observed, but was not known.

Additionally, some of the items on the implementation rubric were not easily observed during a weekly meeting. For example, it is difficult to measure "understands what data are used for" in a regular teacher meeting as the topic may not come up during each week. Lastly, teacher instruction was not assessed, limiting the effect of PLC practices on instructional change.

\section{Directions for Future Research}

PLC practices and teacher team meetings lend themselves to the practice of school psychology. Supporting effective PLC practices could be a way for school psychologists to integrate themselves into a more systems-focused practice. By consulting with teachers on a 
classroom level about their data and instructional change, school psychologists could potentially influence Tier 1 practices, but considerable additional research is needed. Specifically, research could examine if a relationship is present between classroom-level consultation and students identified as at-risk following tier 1 supports. School psychologist consultation with weekly teacher meetings and classroom level support creates a line of inquiry to support the school psychological practice at the universal level.

Student outcomes were not examined during the current study. Future researchers could include student outcomes within PLC implementation studies. Moreover, research is needed regarding the effect of PLCs and teacher collaboration practices on student learning. For example, researchers could study the extent to which multiple weekly teacher meetings affect instructional practices or detract from instructional time.

Within the current study, PLC practices differed across schools, and none had fully implemented the PLC practices from the Missouri PLC Essential Curriculum. Consultation outcomes may have differed if teams who had fully implemented the curriculum were included. More research is needed to examine if familiarity with PLC principles and self-identification as PLCs would influence the ability and motivation of the teachers to make changes.

Lastly, additional research is needed to investigate the leadership structure within the teacher team meetings. Although not studied in the current research, principal presence and participation may influence the PLC practices of a team. Additionally, PLC effectiveness may be influenced by the leadership styles and roles of team members. Previous research has indicated the necessity of leadership in effective PLCs (Thompson Gregg, \& Niska, 2004); however, little or no research has examined leadership styles among teachers and PLC implementation.

\section{Conclusion}


As the practice of school psychology continues to move towards more preventative practices, such as systems-level change and consultation, the integration into PLCs is the next step. The emphasis on collaboration and use of student data to inform instructional practices easily utilizes the unique skill sets of school psychologists. While the changes in PLC practices were not drastic for the four teams in the current study, the data indicated that the intervention was somewhat successful when it had a clear focus and targeted precise areas of need. This study could suggest and lead to future research. 


\section{REFERENCES}

Adelman, H. S., \& Taylor, L. (1997). Toward a scale-up model for replicating new approaches to schooling. Journal of Educational and Psychological Consultation, 8, 197-230.

Andrews, D., \& Lewis, M. (2007). Transforming practice from within: The power of the professional learning community. Professional learning communities: Divergence, depth and dilemmas, 132-147.

Bransford, J. D., \& Stein, B. S. (1984). The IDEAL problem solver. New York: Freeman.

Buck, G. H., Polloway, E. A., Smith-Thomas, A., \& Cook, W. K. (2003). Prereferral intervention processes: A survey of state practices. Exceptional Children, 69, 349-360.

Burns, M. K., \& Coolong-Chaffin, M. (2006). Response to intervention: The role of and effect on school psychology. School Psychology Forum, 1, 3-15.

Burns, M. K., \& Gibbons, K. (2012). Implementing response-to-intervention in elementary and secondary schools: Procedures to assure scientific-based practices ( $2^{\text {nd }}$ ed.). New York, NY: Routledge.

Burns, M. K., Kanive, R., Zaslofsky, A. F., \& Parker, D. C. (2013). Mega-analysis of school psychology blueprint for training and practice domains. School Psychology Forum, 7, 1328.

Burns, M. K., Naughton, M. R., Preast, J. L., Wang, Z., Gordon, R. L., Robb, V., \& Smith, M. L. (2017, in press). Attributes of an effective professional learning community. Journal of Educational and Psychological Consultation.

Burns, M. K., Peters, R., \& Noell, G. H. (2008). Using performance feedback to enhance implementation fidelity of the problem-solving team process. Journal of School Psychology, 46, 537-550. 
Burns, M. K., \& Symington, T. (2002). A meta-analysis of prereferral intervention teams: Student and systemic outcomes. Journal of School Psychology, 40, 437-447.

Burns, M. K., Vanderwood, M. L., \& Ruby, S. (2005). Evaluating the readiness of pre-referral intervention teams for use in a problem-solving model. School Psychology Quarterly, 20, $89-105$.

Calkins, L., Tolan, K., Butler Smith, E., Ochs, M., Steinberg, J. L., Chough, G., ... Marron, A. (2015). Units of Study for Teaching Reading, Grade 4: A workshop curriculum. Portsmouth, NH: Heinemann.

Caplan, G. (1963). Types of mental health consultation. American Journal of Orthopsychiatry, $33,470-481$.

Castillo, J. M., \& Curtis, M. J. (2014). Best practices in systems-level change. In A. Thomas \& P. Harrison (Eds.) Best practices in school psychology VI, 3 (pp. 11-28). Bethesda, MD: National Association of School Psychologists.

Chalfant, J. C., Pysh, M. V., \& Moultrie, R. (1979). Teacher assistance teams: A model for within-building problem-solving. Learning Disabilities Quarterly, 2, 85-96.

Curtis, M. J., \& Metz, L. W. (1986). System level intervention in a school for handicapped children. School Psychology Review, 15, 510-518.

D’Zurilla, T. J., \& Goldfried, M. R. (1971). Problem solving and behavior modification. Journal of Abnormal Psychology, 78, 107-126.

Deutsch, M. (1949). An experimental study of the effects of cooperation and competition upon group process. Human Relations, 2, 199-232.

DuFour, R., \& Eaker, R. (1998). Professional learning communities at work: Best practices for enhancing student achievement. Bloomington, IN: Solution Tree. 
DuFour, R., Eaker, R., \& DuFour, R. (2005). Recurring themes of professional learning communities and the assumptions they challenge. In R. DuFour, R. Eaker, \& R. DuFour (Eds.), On common ground: The power of professional learning communities (pp. 7-31). Bloomington, IN: Solution Tree.

enVision Math Common Core. (2012). New York, NY: Pearson/Scott Foresman - Addison Wesley.

Erchul, W. P. (1987). A relational communication analysis of control in school consultation. Professional School Psychology, 2, 113-124.

Erchul, W. P. (1992). On dominance, cooperation, teamwork, and collaboration in school-based consultation. Journal of Educational and Psychological Consultation, 3, 363-366.

Erchul, W. P. (1999). Two steps forward, one step back: Collaboration in school-based consultation. Journal of School Psychology, 37, 191-203.

Erchul, W. P., \& Martens, B. K. (2002). School Consultation: Conceptual and Empirical Bases of Practice (2 $2^{\text {nd }}$ ed.). New York, NY: Kluwer Academic/Plenum Publishers.

Erchul, W. P., \& Martens, B. K. (2010). School Consultation: Conceptual and Empirical Bases of Practice ( $3^{\text {rd }}$ ed.). New York, NY: Springer.

Erchul, W. P., \& Chewing, T. G. (1990). Behavioral consultation for a request-centered relational communication perspective. School Psychology Quarterly, 5, 1-20.

Ervin, R. A., Schaughency, E., Goodman, S. D., McGlinchey, M. T., Matthews, A. (2006). Merging research and practice agendas to address reading and behavior school-wide. School Psychology Review, 35, 198-223.

Fallon, L. M., Collier-Meek, M. A., Maggin, D. M., Sanetti, L. M. H., \& Johnson, A. H. (2015). Is performance feedback for educators an evidence-based practice? A systematic review 
and evaluation based on single-case research. Exceptional Children, 81, 227-246. doi:

\section{$10.1177 / 0014402914551728$}

Flugum, K. R., \& Reschly, D. J. (1994). Prereferral interventions: Quality indices and outcomes. Journal of School Psychology, 32, 1-14.

Fuchs, D., Fuchs, L. S., \& Bahr, M. W. (1990). Mainstream assistance teams: A scientific basis for the art of consultation. Exceptional Children, 57, 128-139.

Gansle, K. A., \& McMahon, C. M. (1997). Component integrity of teacher intervention management behavior using a student self-monitoring treatment: An experimental analysis. Journal of Behavioral Education, 7, 405-419.

Goldenberg, C. (2004). Successful school change. New York, NY: Colubmia University.

Graden, J. L., Casey, A., \& Christenson, S. L. (1985). Implementing a prereferral intervention system: Part I. the model. Exceptional Children, 51, 377-384.

Gutkin, T. B. (1999a). Collaborative versus directive/prescriptive/expert school-based consultation: Reviewing and resolving a false dichotomy. Journal of School Psychology, $37,161-190$.

Gutkin, T. B. (1999b). The collaboration debate: Finding our way through the maze: Moving forward into the future: A response to Erchul (1999). Journal of School Psychology, 37, 229-241.

Gutkin, T. B., \& Curtis, M. J. (2009). School-based consultation: The science and practice of indirect service delivery. In T. B. Gutkin \& C. R. Reynolds (Eds.), Handbook of school psychology (4 ${ }^{\text {th }}$ ed., pp. 591-635). New York: Wiley.

Gutkin, T. B., Henning-Stout, M., \& Piersal, W. C. (1988). Impact of a district-wide behavioral 
consultation prereferral intervention service on patterns of school psychological service delivery. Professional School Psychology, 3(4), 301-308.

Holcombe, A., Wolery, M., \& Snyder, E. (1994). Effects of two levels of procedural fidelity with constant time delay on children's learning. Journal of Behavioral Education, 4, 49-73.

Hord, S. M. (1997). Professional learning communities: Communities of continuous inquiry and improvement. Austin, TX: Southwest Educational Development Laboratory.

Idol, L., Paolucci-Whitcomb, P., \& Nevin, A. (1986). Collaborative consultation. Rockville, MD: Aspen Publishers.

Johnson, D., \& Johnson, R. (1975). Learning together and alone. Englewood Cliffs, NJ: Prentice-Hall.

Kaiser, L., Rosenfield, S., \& Gravois, T. (2009). Teachers' perceptions of satisfaction, skill development, and skill application after instructional consultation services. Journal of Learning Disabilities, 42, 444-457.

Kampwirth, T. J. (2003). Collaborative consultation in the schools: Effective practices for students with learning and behavior problems ( $5^{\text {th }}$ ed.). Upper Saddle River, NJ: Merrill Prentice Hall.

Karau, S. J., \& Williams, K. D. (1993). Social loafing: A meta-analytic review and theoretical integration. Journal of Personality and Social Psychology, 65, 681-706.

Kemmis, B. L., \& Dunn, W. (1996). Collaborative consultation: The efficacy of remedial and compensatory interventions in school contexts. The American Journal of Occupational Therapy, 50, 709-717.

Klein, A., Fisher, D., \& Frey, N. (2012). Good habits, great readers: Common core edition. Pearson. 
Knotek, S. E., Rosenfield, S. A., Gravois, T. A., \& Babinski, L. M. (2003). The process of fostering consultee development during instructional consultation. Journal of Educational and Psychological Consultation, 14, 303-328.

Kovaleski, J. F., Gickling, E. E., Morrow, H., \& Swank, P. R. (1999). High versus low implementation of instructional support teams: A case for maintaining program fidelity. Remedial and Special Education, 20, 170-183.

Kovaleski, J. F., Tucker, J. A., \& Duffy, D. J. (1995). School reform through instructional support: The Pennsylvania Initiative (Part I). Communiqué, 23(8) (insert).

Lane, K. L., Mahdavi, J. N., \& Borthwick-Duffy, S. (2003). Teacher perceptions of the prereferral intervention process: A call for assistance with school-based interventions. Preventing School Failure, 47, 148-155.

Lewin, K. (1952). Group decision and social change. In G. E. Swanson, T. M. Newcomb, \& E. L. Hartley (Eds.), Readings in Social Psychology: Revised (pp. 459-473). New York: Henry Holt \& Company.

Lewin, K., \& Grabbe, P. (1945). Problems of re-education. Journal of Social Issues, 1(3).

Little, J. W. (2002). Locating learning in teachers' communities of practice: Opening up problems of analysis in records of everyday work. Teaching and Teacher Education, 18, 917-946.

Louis, K. S., \& Marks, H. M. (1998). Does professional community affect the classroom? Teachers' work and student experiences in restructuring schools. American Journal of Education, 106, 532-575. doi: 10.2307/1085627

Martens, B. K., DiGennaro Reed, F. D., \& Magnuson, J. D. (2014). Behavioral consultation: 
Contemporary research and emerging challenges. In W. P. Erchul \& S. M. Sheridan (Eds.), Handbook of research in school consultation (2 $2^{\text {nd }}$ ed., pp. 180-209). New York: Routledge.

McLaughlin, M. W., \& Talbert, J. E. (2006). Building school-based teacher learning communities: Professional strategies to improve student achievment. New York, NY: Teachers College Press.

Missouri Department of Elementary and Secondary Education. (2014). Missouri PLC Overview. Presented at the 2014 Powerful Learning Conference, Osage Beach, MO.

Nellis, L. M. (2012). Maximizing the effectiveness of building teams in response to intervention implementation. Psychology in the Schools, 49, 245-256. doi: 10.1002/pits.21594

Nevin, A., Thousand, J., Paolucci-Whitcomb, P., \& Villa, R. (1990). Collaborative consultation: Empowering public school personnel to provide heterogeneous schooling for all - or, Who rang that bell? Journal of Educational and Psychological Consultation, 1, 41-67.

Noell, G. H., Duhon, G. J., Gatti, S. L., \& Connell, J. E. (2002). Consultation, follow-up, and implementation of behavior management interventions in general education. School Psychology Review, 31, 217-234.

Noell, G. H., \& Gansle, K. A. (2006). Assuring the form has substance. Assessment for Effective Intervention, 32, 32-39.

Noell, G. H., \& Gansle, K. A. (2014). Research examining the relationships between consultation procedures, treatment integrity, and outcomes. In W. P. Erchul \& S. M. Sheridan (Eds.), Handbook of research in school consultation ( $2^{\text {nd }}$ ed., pp. 879-934). New York: Routledge.

Noell, G. H., Witt, J. C., Gilbertson, D. N., Ranier, D. D., \& Freeland, J. T. (1997). Increasing 
teacher intervention implementation in general education settings through consultation and performance feedback. School Psychology Quarterly, 12, 77-88.

Noell, G. H., Witt, J. C., Slider, N. J., Connell, J. E., Gatti, S. L., Williams, K. L., ... Duhon, G. L. (2005). Treatment implementation following behavioral consultation in schools: A comparison of three follow-up strategies. School Psychology Review, 34, 87-106.

Parker, R. I., \& Vannest, K. J. (2009). An improved effect size for single-case research: Nonoverlap of all pairs. Behavior Therapy, 40, 357-367.

Parker, R. I., Vannest, K. J., \& Davis, J. L. (2011). Effect size in single-case research: A review of nine nonoverlap techniques. Behavior Modification, 35, 303-322.

Powers, K., Hagans, K., Busse, R. T. (2008). School psychologists as instructional consultants in a response-to-intervention model. The California School Psychologist, 13, 41-53.

Riley-Tillman, T. C., \& Burns, M. K. (2010). Evaluated educational interventions: Single-case design for measuring response to intervention. New York: Guilford Press.

Rosenfield, S. (1987). Instructional consultation. Hillsdale, NJ: Erlbaum.

Rosenfield, S. (2002). Best practices in instructional consultation. In A. Thomas \& J. Grimes (Eds.), Best practices in school psychology (4th ed., pp. 609-623). Bethesda, MD: National Association of School Psychologists.

Rosenfield, S. (2014). Best practices in instructional consultation and instructional consultation teams. Best practices in school psychology VI, 1, 509-524. Bethesda, MD: National Association of School Psychologists.

Rosenfield, S., \& Gravois, T. A. (1996). Instructional consultation teams: Collaborating for change. New York: Guilford Press.

Rosenfield, S. A., Gravois, T. A., \& Silva, A. E. (2014). Bringing instructional consultation to 
scale: Research and development of IC and IC teams. In W. P. Erchul \& S. M. Sheridan (Eds.), Handbook of research in school consultation (2 ${ }^{\text {nd }}$ ed., pp. 248-275). New York: Routledge.

Ruscio, J. (2008). A probability-based measure of effect size: Robustness to base rates and other factors. Psychological Methods, 13, 19-30. doi: 10.1037/1082-989X.13.1.19

Scruggs, T. E., \& Mastropieri, M. A. (1998). Summarizing single-subject research: Issues and applications. Behavior Modification, 22, 221-242.

Scruggs, T. E., Mastropieri, M. A., \& Casto, G. (1987). The quantitative synthesis of singlesubject research: Methodology and validation. Remedial and Special Education, 8, 24-33.

Senge, P. (1990). The fifth discipline: The art of the learning organization. New York: Currency Doubleday.

Shapiro, E. S. (2000). School psychology from an instructional perspective: Solving big, not little problems. School Psychology Review, 29, 560-572.

Sheridan, S. M., \& Gutkin, T. B. (2000). The ecology of school psychology: Examining and changing our paradigm for the $21^{\text {st }}$ century. School Psychology Review, 29, 485-502.

Sheridan, S. M., Welch, M., Orme, S. F. (1996). Is consultation effective? A review of outcome research. Remedial and Special Education, 17, 341-354.

Shernoff, E. S., Frazier, S. L., Maríñez-Lora, A. M., Lakind, D., Atkins, M. S., Jakobsons, L., ... Patel, D. A. (2016). Expanding the role of school psychologists to support early career teachers: A mixed-method study. School Psychology Review, 45, 226-249.

Sigurðardóttir, A. K. (2010). Professional learning community in relation to school effectiveness. Scandinavian Journal of Educational Research, 54, 395-412. doi:

$10.1080 / 00313831.2010 .508904$ 
Sims, R. L., \& Penny, G. R. (2015). Examination of a failed professional learning community. Journal of Education and Training Studies, 3, 39-45. doi: 10.11114/jets.v3i1.558

Strickler, A., Pfeifer, D., Cameron, A., Robinson, A., Price, C., \& David, M. (2014). Renewing our commitment to kids: Collaborative consultation. Reclaiming Children and Youth, 23, $25-30$.

Tajfel, H. E. (1978). Differentiation between social groups: Studies in the social psychology of intergroup relations. London: Academic Press.

Tharp, R. (1975). The triadic model of consultation. In C. Parker (Ed.), Psychological consultation in the schools: Helping teachers meet special needs (pp. 133-151). Reston, VA: Council for Exceptional Children.

Tharp, R. G., \& Wetzel, R. J. (1969). Behavior modification in the natural environment. San Diego, CA: Academic Press.

Thessin, R. A. (2015). Learning from one urban school district: Planning to provide essential supports for teachers' work in professional learning communities. Educational Planning, $22,15-27$.

Thompson, S. C., Gregg, L., \& Niska, J. M. (2004). Professional learning communities, leadership, and student learning. Research in Middle Level Education Online, 28, 1-15. doi: $10.1080 / 19404476.2004 .11658173$

Tilly, W. D. (2002). Best practices in school psychology as a problem solving enterprise. In A. Thomas \& J. Grimes (Eds.), Best practices in school psychology (4th ed., pp. 21-36). Bethesda, MD: National Association of School Psychologists. 
Truscott, S. D., Cosgrove, G., Meyers, J., \& Eidle-Barkman, K. A. (2000). The acceptability of organizational consultation with prereferral intervention teams. School Psychology Quarterly, 15, 172-206.

Turner, J. C. (1985). Social categorization and the self-concept: Social cognitive theory of group behavior. In E. E. Lawler (Ed.), Advances in group processes, 77-122. Greenwich, CT: JAI.

The University of Chicago School Mathematics Project (2003). Everyday Mathematics. McGraw-Hill Education.

van Dick, R., \& Wagner, U. (2002). Social identification among school teachers: Dimensions, foci, and correlates. European Journal of Work and Organizational Psychology, 11, 129149.

Villa, R. A., Thousand, J. S., Paolucci-Whitcomb, P., \& Nevin, A. (1990). In search of new paradigms for collaborative consultation. Journal of Educational and Psychological Consultation, 1, 279-292.

Vollmer, T. R., Roane, H. S., Ringdahl, J. E., \& Marcus, B. A. (1999). Evaluating treatment challenges with differential reinforcement of alternative behavior. Journal of Applied Behavioral Analysis, 32, 9-23.

Vu, P., Bruckman Shanahan, K., Rosenfield, S., Gravois, T., Koehler, J., Kaiser, L., Berger, J., ... Nelson, D. (2013). Experimental evaluation of instructional consultation teams on teacher beliefs and practices. International Journal of School \& Educational Psychology, $1,67-81$.

Vygotsky, L. (1962). Thought and language. Cambridge, MA: Harvard University Press.

Vygotsky, L. V. (1978). Mind in society: The development of higher psychological processes. 
Cambridge, MA: Harvard University Press.

Witt, J. C., Erchul, W. P., McKee, W. T., Pardue, M. M., \& Wickstrom, K. F. (1991).

Conversational control in school-based consultation: The relationship between consultant and consultee topic determination and consultation outcome. Journal of Educational and Psychological Consultation, 2, 101-116.

Ysseldyke, J., Burns, M., Dawson, P., Kelley, B., Morrison, D., Ortiz, S., ... Telzrow, C. (2006). School psychology: A blueprint for training and practice III. Bethesda, MD: National Association of School Psychologists.

Young, H. L., \& Gaughan, E. (2010). A multiple method longitudinal investigation of prereferral intervention team functioning: Four years in rural schools. Journal of Educational and Psychological Consultation, 20, 106-138. doi: $10.1080 / 10474411003785438$

Zajonc, R. B. (1965). Social facilitation. Science, 149, 269-274.

Zins, J. E., Kratochwill, T. R., \& Elliott, S. N. (Eds.). (1993). Handbook of consultation services for children: Applications in educational and clinical settings. San Francisco, CA: Jossey-Bass. 


\section{APPENDIX A: PLC Implementation Rubric}

\section{PLC Observation Tool}

PLC Team:

Observer:

Date:

School:

Attendees:

Time start:

Time end:

Total time:

Instructions: Circle the rating for each strand item that best describes the actions of the team during the observation period.

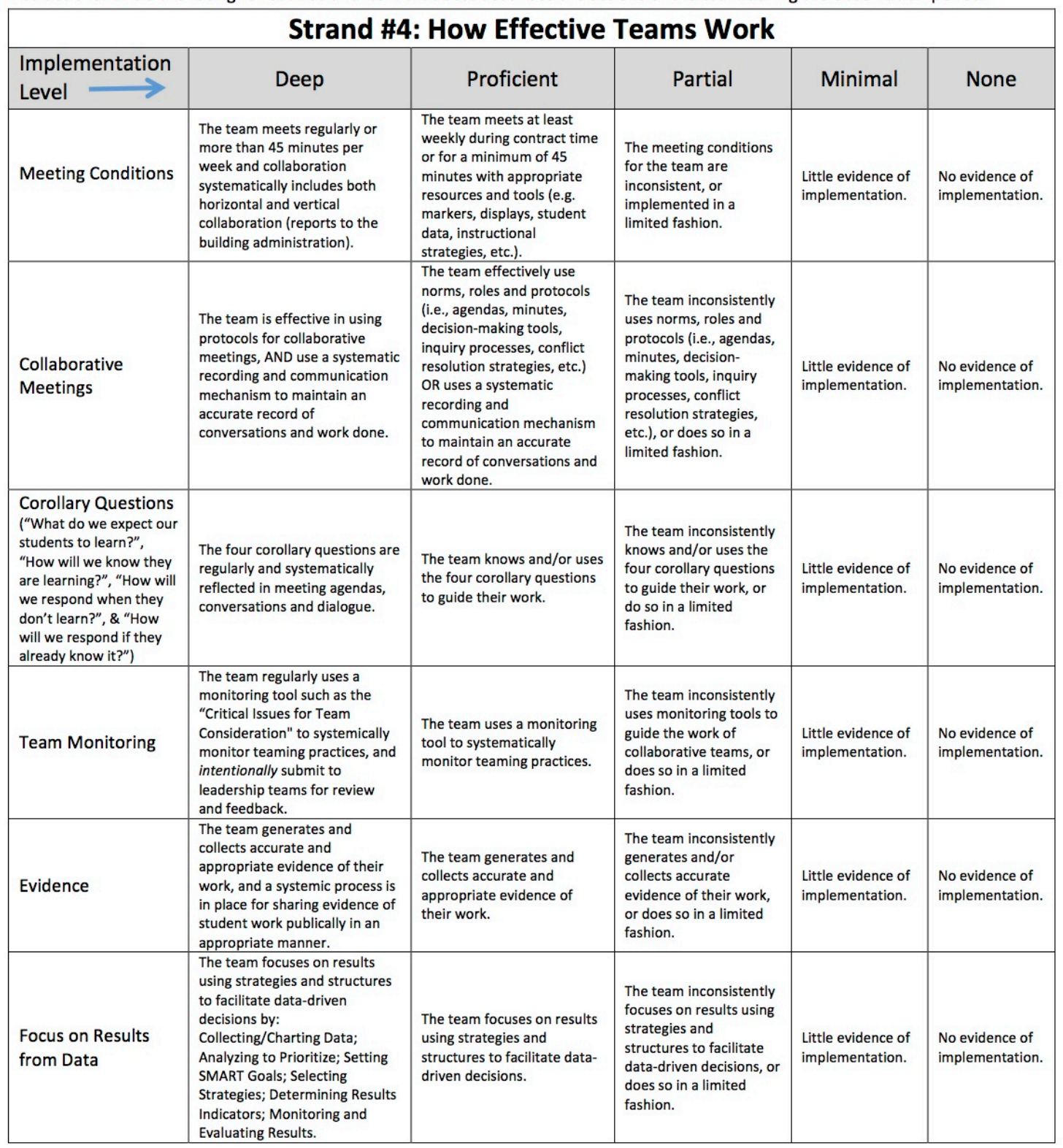




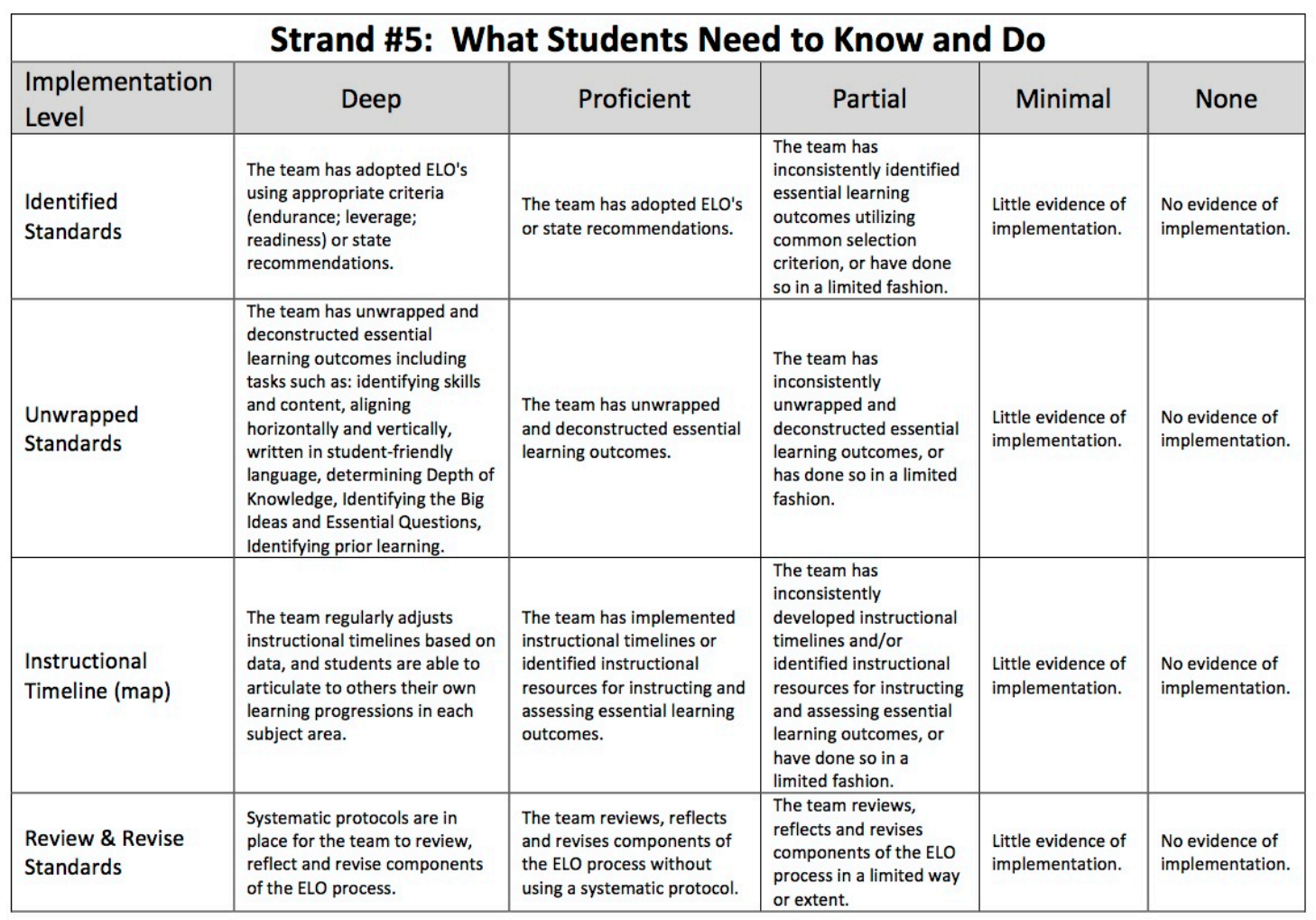




\begin{tabular}{|c|c|c|c|c|c|}
\hline \multicolumn{6}{|c|}{ Strand \#6: Assessment for/of Learning } \\
\hline $\begin{array}{l}\text { Implementation } \\
\text { Level }\end{array}$ & Deep & Proficient & Partial & Minimal & None \\
\hline Purpose and Type & $\begin{array}{l}\text { The team understands the } \\
\text { function and purpose of } \\
\text { assessment and has } \\
\text { developed the appropriate } \\
\text { assessment tools } \\
\text { (classroom formatives, } \\
\text { common formatives, } \\
\text { common summatives), and } \\
\text { uses those tools. }\end{array}$ & $\begin{array}{l}\text { The team understands the } \\
\text { function and purpose of } \\
\text { assessment and has developed } \\
\text { the appropriate assessment } \\
\text { tools (classroom formatives, } \\
\text { common formatives, common } \\
\text { summatives), but does not use } \\
\text { those tools. }\end{array}$ & $\begin{array}{l}\text { The team has } \\
\text { inconsistently } \\
\text { identified the } \\
\text { purpose and } \\
\text { appropriate types of } \\
\text { assessments, or has } \\
\text { done so in a limited } \\
\text { fashion. }\end{array}$ & $\begin{array}{l}\text { Little evidence of } \\
\text { implementation. }\end{array}$ & $\begin{array}{l}\text { No evidence of } \\
\text { implementation. }\end{array}$ \\
\hline Methods & $\begin{array}{l}\text { The team has } \\
\text { collaboratively determined } \\
\text { appropriate assessment } \\
\text { methods aligned to the } \\
\text { standards: selected } \\
\text { response, extended } \\
\text { written response, } \\
\text { performance assessment, } \\
\text { personal communication, } \\
\text { appropriate scoring guides, } \\
\text { auditing and revising as } \\
\text { needed. }\end{array}$ & $\begin{array}{l}\text { The team has collaboratively } \\
\text { determined appropriate } \\
\text { assessment methods aligned to } \\
\text { the standards, but does not } \\
\text { use those assessment } \\
\text { methods. }\end{array}$ & $\begin{array}{l}\text { The team has } \\
\text { inconsistently } \\
\text { determined } \\
\text { appropriate } \\
\text { assessment methods, } \\
\text { or has done so in a } \\
\text { limited fashion. }\end{array}$ & $\begin{array}{l}\text { Little evidence of } \\
\text { implementation. }\end{array}$ & $\begin{array}{l}\text { No evidence of } \\
\text { implementation. }\end{array}$ \\
\hline Feedback & $\begin{array}{l}\text { The team has developed } \\
\text { and applied strategies and } \\
\text { techniques for providing } \\
\text { timely specific descriptive } \\
\text { feedback. }\end{array}$ & $\begin{array}{l}\text { The team has developed } \\
\text { techniques for providing timely } \\
\text { specific descriptive feedback, } \\
\text { but has not applied those } \\
\text { techniques. }\end{array}$ & $\begin{array}{l}\text { Teams have } \\
\text { inconsistently } \\
\text { developed and } \\
\text { applied } \\
\text { strategies/techniques } \\
\text { for providing } \\
\text { descriptive feedback, } \\
\text { or has done so in a } \\
\text { limited fashion. }\end{array}$ & $\begin{array}{l}\text { Little evidence of } \\
\text { implementation. }\end{array}$ & $\begin{array}{l}\text { No evidence of } \\
\text { implementation. }\end{array}$ \\
\hline $\begin{array}{l}\text { Student } \\
\text { Involvement }\end{array}$ & $\begin{array}{l}\text { The team has developed } \\
\text { and applied strategies for } \\
\text { involving students in the } \\
\text { assessment process in a } \\
\text { systematic manner: Clear } \\
\text { and understandable } \\
\text { learning targets, Student } \\
\text { self-monitoring, Student } \\
\text { data notebooks, Goal- } \\
\text { setting, Student-led } \\
\text { conferences, etc.. }\end{array}$ & $\begin{array}{l}\text { The team has developed and } \\
\text { applied strategies for involving } \\
\text { students in the assessment } \\
\text { process, but not in a systematic } \\
\text { manner. }\end{array}$ & $\begin{array}{l}\text { The team has } \\
\text { inconsistently } \\
\text { developed and } \\
\text { applied strategies for } \\
\text { involving students in } \\
\text { the assessment } \\
\text { process, or has done } \\
\text { so in a limited } \\
\text { fashion. }\end{array}$ & $\begin{array}{l}\text { Little evidence of } \\
\text { implementation. }\end{array}$ & $\begin{array}{l}\text { No evidence of } \\
\text { implementation. }\end{array}$ \\
\hline Scoring & $\begin{array}{l}\text { The team regularly and } \\
\text { systematically utilizes } \\
\text { answer keys and/or scoring } \\
\text { guides to collectively score } \\
\text { student work. }\end{array}$ & $\begin{array}{l}\text { The team utilizes answer keys } \\
\text { and/or scoring guides. }\end{array}$ & $\begin{array}{l}\text { The team } \\
\text { inconsistently utilizes } \\
\text { scoring guides to } \\
\text { collectively score } \\
\text { student work, or does } \\
\text { so in a limited } \\
\text { fashion. }\end{array}$ & $\begin{array}{l}\text { Little evidence of } \\
\text { implementation. }\end{array}$ & $\begin{array}{l}\text { No evidence of } \\
\text { implementation. }\end{array}$ \\
\hline Data & $\begin{array}{l}\text { Systematic and systemic } \\
\text { protocols are utilized by } \\
\text { the team to analyze } \\
\text { student assessment } \\
\text { (effect) data and adult } \\
\text { behavior (cause) data with } \\
\text { fidelity. Data is regularly } \\
\text { used to audit assessments } \\
\text { for validity and reliability. }\end{array}$ & $\begin{array}{l}\text { The team analyzes student } \\
\text { assessment (effect) data and } \\
\text { adult behavior (cause) data to } \\
\text { inform instructional decisions } \\
\text { and make adjustments, but } \\
\text { without a systematic protocol. }\end{array}$ & $\begin{array}{l}\text { The team } \\
\text { inconsistently } \\
\text { analyzes student } \\
\text { assessment data to } \\
\text { inform instructional } \\
\text { decisions and make } \\
\text { adjustments, or does } \\
\text { so in a limited } \\
\text { fashion. }\end{array}$ & $\begin{array}{l}\text { Little evidence of } \\
\text { implementation. }\end{array}$ & $\begin{array}{l}\text { No evidence of } \\
\text { implementation. }\end{array}$ \\
\hline Grading Practices & $\begin{array}{l}\text { Systematic, school-wide } \\
\text { decisions regarding } \\
\text { research-based grading } \\
\text { practices have been made } \\
\text { and implemented with } \\
\text { fidelity. }\end{array}$ & $\begin{array}{l}\text { The team has examined } \\
\text { current grading practices and } \\
\text { the impact on student learning, } \\
\text { making collective decisions } \\
\text { regarding appropriate grading } \\
\text { practices. }\end{array}$ & $\begin{array}{l}\text { The team has } \\
\text { inconsistently } \\
\text { examined current } \\
\text { grading practices and } \\
\text { the impact on student } \\
\text { learning, or has done } \\
\text { so in a limited } \\
\text { fashion. }\end{array}$ & $\begin{array}{l}\text { Little evidence of } \\
\text { implementation. }\end{array}$ & $\begin{array}{l}\text { No evidence of } \\
\text { implementation. }\end{array}$ \\
\hline
\end{tabular}

Adapted from MO PLC Implementation Rubric 


\section{VITA}

June Preast is a doctoral candidate in the School Psychology program at the University of Missouri and is currently completing her doctoral internship with North Kansas City School District. Originally from Wilmington, North Carolina, June has earned Bachelors of Science in Neuroscience, Masters of Arts in School Psychology, and Certificate of Advanced Study in School Psychology degrees from East Carolina University. Prior to attending the University of Missouri, June practiced school psychology for two years in Eastern North Carolina.

During her tenure at Mizzou, she worked in the research labs of Dr. Matthew Burns and Dr. Chad Rose. Through her work in those research labs, she is listed as an author on 12 peerreviewed journals, 1 practitioner journal, and 2 book chapters. June also worked with a grant providing mental health services to schools in rural Missouri. And she is a student reviewer for the Assessment and Effective Intervention journal.

June's research agenda focuses primarily on identifying and implementing systemic change to support the academic and behavioral needs of students. She uses a primary prevention, multi-tiered systems of support approach to educational decision-making and programming. As such, she has studied the impact of academic interventions to address behavioral issues, the influence of psycho-social factors related to bullying and victimization, the importance of using data to inform academic and behavioral intervention choices, and the attributes of effective teacher teams. Already defended and accepted for publication, her dissertation used a multiple baseline design to examine the effects of consultation on the implementation of professional learning communities.

Following the completion of her internship, June will join the faculty at the University of Alabama as a tenure-track Assistant Professor in School Psychology. 